Hydrol. Earth Syst. Sci., 16, 2893-2913, 2012

www.hydrol-earth-syst-sci.net/16/2893/2012/

doi:10.5194/hess-16-2893-2012

(C) Author(s) 2012. CC Attribution 3.0 License.

(c) (i)

\title{
Towards an integrated soil moisture drought monitor for East Africa
}

\author{
W. B. Anderson ${ }^{1}$, B. F. Zaitchik ${ }^{2}$, C. R. Hain ${ }^{3}$, M. C. Anderson ${ }^{4}$, M. T. Yilmaz ${ }^{4}$, J. Mecikalski ${ }^{5}$, and L. Schultz ${ }^{5}$ \\ ${ }^{1}$ Department of Geography and Environmental Engineering, The Johns Hopkins University, Baltimore, MD, USA \\ ${ }^{2}$ Department of Earth and Planetary Sciences, The Johns Hopkins University, Baltimore, MD, USA \\ ${ }^{3}$ Earth System Science Interdisciplinary Center, University of Maryland, College Park, MD, USA \\ ${ }^{4}$ Hydrology and Remote Sensing Laboratory, USDA-ARS, Beltsville, MD, USA \\ ${ }^{5}$ Atmospheric Science Department, National Space Science and Technology Center, University of Alabama in Huntsville, \\ Huntsville, AL 35805, USA
}

Correspondence to: W. B. Anderson (weston.b.anderson@gmail.com)

Received: 19 March 2012 - Published in Hydrol. Earth Syst. Sci. Discuss.: 5 April 2012

Revised: 29 June 2012 - Accepted: 26 July 2012 - Published: 22 August 2012

\begin{abstract}
Drought in East Africa is a recurring phenomenon with significant humanitarian impacts. Given the steep climatic gradients, topographic contrasts, general data scarcity, and, in places, political instability that characterize the region, there is a need for spatially distributed, remotely derived monitoring systems to inform national and international drought response. At the same time, the very diversity and data scarcity that necessitate remote monitoring also make it difficult to evaluate the reliability of these systems. Here we apply a suite of remote monitoring techniques to characterize the temporal and spatial evolution of the 2010-2011 Horn of Africa drought. Diverse satellite observations allow for evaluation of meteorological, agricultural, and hydrological aspects of drought, each of which is of interest to different stakeholders. Focusing on soil moisture, we apply triple collocation analysis (TCA) to three independent methods for estimating soil moisture anomalies to characterize relative error between products and to provide a basis for objective data merging. The three soil moisture methods evaluated include microwave remote sensing using the Advanced Microwave Scanning Radiometer - Earth Observing System (AMSR-E) sensor, thermal remote sensing using the Atmosphere-Land Exchange Inverse (ALEXI) surface energy balance algorithm, and physically based land surface modeling using the Noah land surface model. It was found that the three soil moisture monitoring methods yield similar drought anomaly estimates in areas characterized by extremely low or by moderate vegetation cover, particularly during the below-average 2011 long rainy season. Systematic discrepancies were found, however, in regions of
\end{abstract}

moderately low vegetation cover and high vegetation cover, especially during the failed 2010 short rains. The merged, TCA-weighted soil moisture composite product takes advantage of the relative strengths of each method, as judged by the consistency of anomaly estimates across independent methods. This approach holds potential as a remote soil moisturebased drought monitoring system that is robust across the diverse climatic and ecological zones of East Africa.

\section{Introduction}

The 2010-2011 Horn of Africa drought affected over 13 million people (Ledwith, 2011). The failure of the October to December 2010 "short" rains and delayed arrival of the April to June 2011 "long" rains caused crop failures across Somalia, Ethiopia and Kenya. The price of food reflected the effect of crop failures on a food-insecure region; the price of maize in Kenya, for example, rose $246 \%$ over the span of a year (Funk, 2011). On 7 June 2011, the Famine Early Warning System Network (FEWS NET) issued a statement declaring the crisis to be "the most severe food security emergency in the world today". Over the course of the next two months, the crises worsened and the United Nations declared famine in five regions of Somalia (United Nations, 2011).

In broad terms, the drought and subsequent famine were anticipated by forecasters. The emerging La Niña event in summer 2010, occurring on top of steady Indian Ocean warming that has been associated with reduced precipitation in the Horn of Africa, and combined with weakened social

Published by Copernicus Publications on behalf of the European Geosciences Union. 
resilience due to poor harvests and rangeland conditions in recent years were recognized as a significant risk to the region (Funk, 2011). Given such warnings - albeit warnings that come with substantial uncertainty - national governments and international actors were in position to respond quickly when the rains failed. The failure to muster adequate disaster mitigation can be attributed largely to political instability and to the limitations of what can be accomplished in reactive drought response. At the same time, adequate emergency intervention is also limited by inadequate access to reliable, spatially distributed drought monitoring information available in near real-time. In situ monitoring networks, though critical to drought planning and response, are limited in this regard, both practically and inherently. While the Horn of Africa has limited networks and is affected by political instability, even if measurements were available, it would be difficult to capture the spatial variability of drought impacts using point monitoring stations alone.

For this reason, there has been considerable interest in developing East African drought monitoring systems based on remotely sensed and model-derived analyses. The most advanced of these systems is the Famine Early Warning System Network (FEWS NET), which operates throughout East Africa, Afghanistan, and Central America. A United States Agency for International Development (USAID) project in operation since 1985, FEWS NET combines local socioeconomic information with agricultural production and precipitation information to predict food security conditions (Funk, 2009). Satellite data feed into the system in the form of remotely sensed vegetation indices and precipitation estimates, while a Water Requirements Satisfaction Index (WRSI) model is used to gauge crop conditions. Additional remote drought monitors covering East Africa include the Experimental African Drought Monitor maintained by the Land Surface Hydrology Group at Princeton, which provides near real-time drought monitoring for all of Africa using the variable infiltration capacity (VIC) hydrological model and a long-term retrospective meteorological reanalysis (Sheffield et al., 2008) to quantify current drought conditions across the continent ${ }^{1}$. The International Research Institute for Climate and Society Map Room ${ }^{2}$ serves regional precipitation anomaly maps derived from the Climate Anomaly Monitoring System Outgoing Longwave Radiation Precipitation Index (CAMS_OMI; Janowiak and Xie, 1999), while the Global Drought Monitor provides drought monitoring that includes coverage of Africa at a spatial resolution of $\sim 100 \mathrm{~km}$ and at monthly intervals ${ }^{3}$. The Global Drought Monitor is based on the Standardized Precipitation Index (SPI) and the Palmer Drought Severity Index (PDSI).

Outside of Africa, there are numerous examples of experimental and operational drought monitoring systems that rely

\footnotetext{
${ }^{1}$ http://hydrology.princeton.edu/monitor

${ }^{2} \mathrm{http}$ ://iridl.ldeo.columbia.edu/maproom/

${ }^{3}$ http://drought.mssl.ucl.ac.uk
}

on either remote sensing or hydrological models. In the US, these include the Vegetation Drought Response Index (VegDRI), which monitors drought conditions for the continental US by combining climate-related variables with satellitederived vegetation condition information obtained using Advanced Very High Resolution Radiometer (AVHRR)-based vegetation indices (Brown, 2010), and the University of Washington Experimental Surface Water Monitor (Wood, 2008), based on a multi-model monitor employing VIC (Liang et al., 1994), Sacramento Soil Moisture Accounting (SAC-SMA; Burnash, 1995), Community Land Model (CLM; Dai et al., 2003; Lawrence et al., 2011), Catchment (Koster et al., 2000), and Noah (Chen et al., 1996; Ek et al., 2003; Koren et al., 1999) land-surface models (LSMs). Other AVHRR-derived drought indices include the Vegetation Condition Index (VCI), derived from AVHRR Normalized Difference Vegetation Index (NDVI) data and the Temperature Condition Index (TCI), which is calculated using AVHRR thermal data (Kogan, 1990, 1995), as well as the Vegetation Health Index (VHI) which combines the VCI and TCI (Kogan, 1997). Remotely sensed land-surface temperature and vegetation cover information have also been combined within the Atmosphere-Land Exchange Inverse (ALEXI) surface energy balance algorithm (Anderson et al., 1997, 2007a) to generate an Evaporative Stress Index (ESI), quantifying anomalies in the ratio of actual to potential evapotranspiration (Anderson et al., 2011a,b).

Combined satellite/model drought monitoring tools are also becoming more common. Data assimilation systems merge observations with physically based models, using the model to provide spatially and temporally complete estimates of all drought-relevant hydrologic variables and the observation record to correct for model error. Examples include the North American Land Data Assimilation System (NLDAS; Sheffield et al., 2012; Xia et al., 2012) and Gravity Recovery and Climate Experiment (GRACE) Data Assimilation System ${ }^{4}$ Drought Monitors. The NLDAS Drought Monitor covers the continental US and is based on output from the Mosaic (Koster and Suarez, 1996), VIC (Liang et al., 1994), Sacramento Soil Moisture Accounting (SACSMA; Burnash, 1995), and Noah (Chen et al., 1996; Ek et al., 2003; Koren et al., 1999) LSMs. These models are uncoupled and forced mainly by observational data to avoid numerical weather prediction forcing biases. Anomalies and percentiles in soil moisture, stream flow and runoff are computed for each individual model and for ensemble averages with respect to climatological normal conditions computed for 1980 to $2007^{5}$ (Sheffield et al., 2012; Xia et al., 2012). The GRACE Data Assimilation System Drought Monitor produces weekly updated soil moisture and drought indicators. Terrestrial water storage observations from GRACE

\footnotetext{
${ }^{4}$ http://drought.unl.edu/MonitoringTools/

NASAGRACEDataAssimilation.aspx

${ }^{5}$ http://www.emc.ncep.noaa.gov/mmb/nldas/drought/
} 
satellite data are integrated with additional meteorological measurements using an ensemble Kalman filter within the Catchment Land Surface Model (Zaitchik et al., 2008). Current hydrologic conditions are expressed as percentiles relative to baseline measurements from 1948 to 2009.

For all of the value that these satellite- and model-based drought monitors provide, a monitoring system based on a single algorithm or observational record is prone to systematic and/or transient error. This is a particular concern in data poor regions like East Africa, where it is not possible to evaluate a remote drought monitor comprehensively against in situ observations. In this context, it is desirable to apply multiple, independent methods to remote drought monitoring in order to characterize systematic differences between methods, to identify and address limitations in particular techniques, and to generate consensus drought indices. Merging independent methods to generate a consensus drought index will help reduce the random and systematic error components of the input datasets.

In this paper, we examine the 2010-2011 Horn of Africa drought using remotely sensed estimates of soil moisture, evapotranspiration, precipitation, and terrestrial water storage. The relative merits of each observational technique are discussed in qualitative terms, and soil moisture estimates are then assessed quantitatively and merged into a consensus drought monitor product by applying a least squares algorithm that depends on triple collocation analysis (TCA)based errors associated with soil moisture anomalies derived from ALEXI, AMSR-E, and the Noah LSM. TCA is a statistical method for characterizing consensus and discrepancies across multiple independent datasets. Though developed originally for oceanographic applications (Stoffelen, 1998), the method has recently been applied successfully to the problem of estimating soil moisture variability at regional to global scale (Scipal et al., 2008; Hain et al., 2011; Parinussa et al., 2011; Yilmaz et al., 2012). TCA is of particular value in regions that lack in situ soil moisture monitoring networks, as consensus anomaly estimates derived from multiple independent datasets can be interpreted as a measure of confidence in the absence of adequate in situ evaluation data. The least squares-based merging technique applied to these TCA-based error estimates was chosen as an objective offline merging method, because it requires minimal assumptions be made about the input datasets and their error characteristics.

\section{Methods}

\subsection{Soil moisture estimates}

\subsubsection{AMSR-E passive microwave sensor}

The Advanced Microwave Scanning Radiometer for EOS (AMSR-E) is a passive microwave-radiometer system mounted on the Aqua satellite. From July 2002 to
September 2011, AMSR-E retrievals of microwave brightness temperature were used to derive estimates of surface soil moisture with near-daily coverage. The instrument is currently experiencing an antenna malfunction that may be terminal, but similar microwave measurements are available on existing and planned satellite missions. Several algorithms have been developed to estimate soil moisture on the basis of AMSR-E retrievals. In this application, we use the soil moisture product derived using the Land Parameter Retrieval Model (LPRM) developed by Vrije Universiteit Amsterdam (VUA) and the National Aeronautics and Space Administration (NASA). The LPRM algorithm relies on C-band observations and can utilize $\mathrm{X}$-band observations under conditions of radio frequency interference in the $\mathrm{C}$-band (Owe et al., 2008). The LPRM product was chosen over other available AMSR-E soil moisture products on the basis of previously published comparisons (Rudiger et al., 2008; Wagner et al., 2007; Draper et al., 2009; Hain et al., 2011). The product produces daily ascending and descending estimates at 01:30 a.m. and 01:30 p.m. (local time). To avoid complications such as sun glint and strong temperature gradients, which are more prevalent in the ascending passes when using the VUA algorithm, only descending passes (01:30 a.m. LT) of the AMSR-E measurements were used (Kerr and Njoku, 1990; Crow et al., 2010).

While the temporal resolution of AMSR-E is relatively high, the spatial resolution remains coarse at $\sim 25 \mathrm{~km}$ with a sensing depth of only $\sim 1 \mathrm{~cm}$. The native spatial resolution of AMSR-E and the remapping used in the LPRM algorithm are further discussed in Sect. 2.3.

\subsubsection{ALEXI thermal infrared model}

The Atmosphere-Land Exchange Inverse (ALEXI) model is a thermal infrared-based diagnostic model that employs the two-source energy balance (TSEB) model of Norman et al. (1995), representing the land surface as a composite of soil and vegetation cover, while coupling with an atmospheric boundary layer model to internally simulate landatmosphere feedback on near-surface air temperature (Anderson et al., 1997, 2007a). ALEXI solves the surface energy balance for latent and sensible heat components using time-differential land surface temperature measurements taken from geostationary satellites between $\sim 1.5 \mathrm{~h}$ after local sunrise and $\sim 1.5 \mathrm{~h}$ before local noon. The morning surface temperature rise is largely governed by soil moisture conditions and available energy. Wet conditions in the surface layer increase latent heat flux and therefore decrease morning temperature amplitude, while dry conditions lead to increased sensible heat flux and therefore higher morning temperature amplitudes. Anderson et al. (2007b) and Hain et al. $(2009,2011)$ detail a method of relating latent heat fluxes retrieved by ALEXI to soil moisture conditions by applying a soil moisture stress function between the fraction of actual to potential evaporation $\left(f_{\mathrm{PET}}\right)$ and the fraction of available 
water. A relation between $f$ PET and retrieved soil moisture values based on ALEXI estimates of $f_{\mathrm{PET}}$ may be derived that is of the following form:

$\theta_{\mathrm{ALEXI}}=\left(\theta_{\mathrm{fc}}-\theta_{\mathrm{wp}}\right) \cdot f_{\mathrm{PET}}+\theta_{\mathrm{wp}}$

where $\theta_{\text {ALEXI }}$ is the soil moisture value reported by ALEXI, $\theta_{\mathrm{fc}}$ and $\theta_{\mathrm{wp}}$ are the soil moisture at field capacity and wilting point, respectively, and $f_{\mathrm{PET}}$ is the fraction of actual to potential evapotranspiration. Note that while Eq. (1) requires information about SM at field capacity and wilting point, these values drop out during the computation of standardized grid cell anomalies describing the deviation from mean conditions for each 8-day composite period at each pixel in the study period. Hain et al. (2009) validated this relationship by comparing soil moisture observations from the Oklahoma Mesonet to ALEXI soil moisture retrievals.

ALEXI was executed at 6-km spatial resolution over the Horn of Africa domain using hourly land-surface temperature and insolation products developed by the Land Surface Analysis Satellite Applications Facility (LSA SAF), using imagery from the primary Meteosat Second Generation (MSG) geostationary satellite (landsaf.meteo.pt) (see Anderson et al., 2011b). ALEXI output was then aggregated to the $25-\mathrm{km}$ grid associated with the AMSR-E product. As a thermal remote sensing model, ALEXI is limited to cloud-free sky conditions during the morning hours when the ground is visible to the thermal satellite sensor.

\subsubsection{Noah land surface model}

Offline simulations of Noah LSM version 3.2 were performed using Global Data Assimilation System (Derber et al., 1991) meteorological forcing supplemented by the three hourly precipitation estimates from the gauge-adjusted Tropical Rainfall Measurement Mission (TRMM) Multisensor Precipitation Analysis (TMPA), version 6 (product 3B42; Huffman et al., 2007). Noah is a one-dimensional model that evaluates the surface energy and water budgets to calculate the distribution of soil moisture in the soil column. Evapotranspiration is defined as the sum of canopy transpiration, evaporation from the top soil layer, and evaporation of canopy-intercepted water (Ek et al., 2003; Chen et al., 1996). Soil moisture is a prognostic field for each of the model's four vertical soil layers, which allows for the diagnosis of both near-surface and root zone soil moisture.

An LSM-based prediction of soil moisture offers the benefit of providing continuous estimates under all weather and surface cover conditions, as opposed to ALEXI and AMSR-E, which are hindered by clouds and dense vegetation, respectively. Model output was stored and evaluated at three-hour intervals, but only outputs aligned with the overpass times of AMSR-E retrievals were used in this analysis to ensure a consistent comparison. The AMSR-E descending overpass time for the Horn of Africa is 04:30 GMT which corresponds to the 03:00-06:00 GMT output interval of Noah. Model simulations were run at a spatial resolution of $25 \mathrm{~km}$ to match the spatial resolution of the AMSR-E measurements. Noah simulations in this region are the subject of ongoing evaluation, with early results indicating that simulations forced with GDAS meteorology supplemented by TMPA precipitation provide reasonable results over much of the Nile Basin and surroundings (Zaitchik et al., 2010).

\subsection{Supplementary satellite-derived observations}

Additional data sources were included in the anomaly analyses to depict a more complete hydrologic picture. For all datasets, we compiled gridded data for East Africa for the period 2003-2011 and then calculated anomalies relative to the 2003-2010 climatology:

- precipitation: three hourly TMPAv6 precipitation estimates ( $25 \mathrm{~km}$ resolution), averaged over 8-day composite periods, were used to compare the 2010-2011 seasonal rains to those from 2003-2010.

- vegetation index: 16-day, $0.05^{\circ}$ resolution composited MODerate Resolution Imaging Spectroradiometer (MODIS) NDVI estimates (product MOD13C1; Huete et al., 2002) were used to evaluate drought impacts on biomass production.

- terrestrial water storage: monthly estimates of terrestrial water storage anomaly derived from GRACE were used as an independent assessment of drought conditions. GRACE anomalies for the area of interest were extracted from the CSR level 2 GRACE gridded land product, release 4 , with a $300 \mathrm{~km}$ smoothing radius. Land scaling factors were included in data extraction (Swenson and Wahr, 2006) ${ }^{6}$.

\subsection{Comparison and data merging}

For TCA, the three independent soil moisture datasets (LPRM, Noah and ALEXI) were standardized to a common spatial resolution, depth, frequency, and unit of measure.

\subsubsection{Resampling to a common grid}

Each dataset was resampled using a nearest neighbor resample to match the $0.25 \times 0.25^{\circ}$ flat grid of the LPRM data. The ALEXI model was run with a $6 \mathrm{~km}$ spatial resolution, which necessitated an aggregation of the data prior to resampling. The Noah LSM was run at $25 \mathrm{~km}$ spatial resolution, requiring only a resample to match the chosen grid.

\footnotetext{
${ }^{6}$ GRACE land data were processed by Sean Swenson, supported by the NASA MEASURES Program, and are available at http:// grace.jpl.nasa.gov.
} 


\subsubsection{Creating composite time periods}

Although each methodology is capable of producing daily measurements for the domain of the analysis under favorable conditions, the satellite-derived records suffered from data gaps. LPRM gaps are a product of the overpass repeat cycle of Aqua, which results in spatial swaths of missing data on a regular repeat cycle, and of interference from precipitation, dense vegetation, radio signals or frozen ground. Retrievals that were flagged as poor quality due to such interference were removed from the analysis. Missing values were present in the ALEXI model, because the algorithm requires morning observations of radiometric surface temperature, which can only be observed for cloud-free regions. This creates seasonally repeating areas of sparse data coverage in climatologically cloudy regions. Gap-filling algorithms for ALEXI have been developed to generate daily ET estimates (Anderson et al., 2007a), but they were not utilized in this study so as to focus only on direct retrievals of soil moisture (rather than interpolated values). Eight-day composites across the period of study were created for each dataset to avoid oversampling in the analysis due to seasonal weather events. All available observations were averaged within a given compositing period.

\subsubsection{Estimating root zone soil moisture for all products}

To standardize the depth of soil moisture estimate across LPRM, ALEXI, and Noah, each dataset was converted to an estimate of soil moisture through the root zone. For this study, the root zone was defined as the top $1 \mathrm{~m}$ of the soil column.

ALEXI provides a single column-integrated soil moisture estimate that reflects soil moisture from the surface to the rooting depth of the vegetation: surface soil wetness cools the surface through direct evaporation, while root zone soil moisture leads to cooling through plant transpiration. The degree to which near-surface vs. deeper root zone soil moisture influences the ALEXI signal is assumed to be related to the observed green vegetation cover fraction $\left(f_{\mathrm{c}}\right.$; Hain et al., 2009, 2011), as described further below.

The Noah LSM produces a stratified soil moisture estimate that is divided into four layers: $0-10 \mathrm{~cm}, 10-40 \mathrm{~cm}, 40$ $100 \mathrm{~cm}$ and $100-200 \mathrm{~cm}$. For the purposes of this study, the first layer $(0-10 \mathrm{~cm})$ was considered the surface layer, while the depth-weighted average of the first three layers (together $0-100 \mathrm{~cm}$ ) was considered the root zone.

LPRM produces soil moisture estimates for only the top layer of soil $(\sim 1 \mathrm{~cm})$. An exponential filter (Eq. 2) was used to extrapolate these measurements and simulate infiltration of surface soil moisture into the root zone. The filter used was developed by Wagner et al. (1999) and has been employed by Ceballos et al. (2005), Albergel et al. (2008) and Hain et al. (2011). The filter applies a two-layer water balance that estimates the root zone soil moisture using a surface soil moisture measurement and a characteristic time of variation between the surface and root zones (Wagner et al., 1999):

$\theta\left(t_{n}\right)_{\text {LPRM_rz }}=\frac{\sum \theta\left(t_{i}\right)_{\text {LPRM_ff }_{\text {f }}} e^{-\frac{t_{n}-t_{i}}{\tau}}}{\sum e^{-\frac{t_{n}-t_{i}}{\tau}}}$,

where $\theta\left(t_{i}\right)_{\text {LPRM_sf }}$ represents the soil moisture retrieval for a past day $t_{i}, \theta(t n)_{\text {LPRM_rz }}$ represents the root zone soil moisture estimation for a given day $\left(t_{n}\right)$, and $\tau$ represents the characteristic time of variation between the surface layer and root zone in the soil profile. Optimal values for $\tau$ were calculated as those that maximized the correlation between the Noah LSM root-zone estimates and root-zone estimates computed by running the Noah $0-10 \mathrm{~cm}$ soil moisture estimates from 2003-2011 through the exponential filter (Eq. 2).

The true depth of the soil moisture estimate produced by ALEXI is related to the fraction of green vegetation cover $\left(f_{\mathrm{c}}\right)$. Over bare soil, the latent heat is dominated by the evaporation from the top layer of soil, similar to the sensing depth of microwave sensors such as AMSR-E (Hain et al., 2011; Crow and Zhan, 2007). Over densely vegetated areas $\left(f_{\mathrm{c}}>75 \%\right)$, ALEXI latent heat is dominated by the evapotranspiration from the canopy layer, which is indicative of soil moisture in the root zone. This relationship is approximated by Eq. (3):

$\theta_{\text {ALEXI }}=\left(1-f_{\mathrm{c}}\right) \theta_{\text {ALEXI_sf }}+f_{\mathrm{c}} \theta_{\text {ALEXI_rz }}$,

where $\theta_{\text {ALEXI }}$ is the total profile soil moisture estimate retrieved from ALEXI, $\theta_{\text {ALEXI_sf }}$ and $\theta_{\text {ALEXI_rz }}$ are respectively the surface and root zone soil moistures, and $f_{\mathrm{c}}$ is the fractional green vegetation cover. For this study, $\theta_{\text {ALEXI_sf }}$ and $\theta_{\text {ALEXI_rz }}$ are not independently retrieved, but are included in Eq. (3) to illustrate the process conceptually. LPRM and Noah soil moisture measurements were scaled using the same methodology so that the physical value being measured remains consistent across all products:

$\theta_{\text {LPRM }}=\left(1-f_{\mathrm{c}}\right) \theta_{\text {LPRM_sf }}+f_{\mathrm{c}} \theta_{\text {LPRM_rz }}$

$\theta_{\text {Noah }}=\left(1-f_{\mathrm{c}}\right) \theta_{\text {Noah_sf }}+f_{\mathrm{c}} \theta_{\text {Noah_rz }}$

where $\theta_{\text {LPRM_sf }}$ is defined as the LPRM surface soil moisture retrieval and $\theta_{\text {LPRM_rz }}$ is the estimate produced by the exponential filter. $\theta_{\text {Noah_sf }}$ is the first Noah soil moisture output layer $(0-10 \mathrm{~cm})$, and $\theta_{\text {Noah_rz }}$ is the sum of the first through third layers $(0-10 \mathrm{~cm}, 10-40 \mathrm{~cm}$ and $40-100 \mathrm{~cm})$.

The green vegetative cover of a pixel for LPRM and Noah was determined using MODIS 16-day NDVI estimates (MOD13C1) and the linear relationship of Gutman and Ignatov (1998):

$f_{\mathrm{c}}=\frac{\left(\mathrm{NDVI}-\mathrm{NDVI}_{0}\right)}{\left(\mathrm{NDVI}_{100}-\mathrm{NDVI}_{0}\right)}$.

$\mathrm{NDVI}_{0}$ refers to the minimum observed NDVI for the entire area of study over the entire time period. In this case, $\mathrm{NDVI}_{0}$ 
was calculated by averaging the five smallest observed values. $\mathrm{NDVI}_{100}$ refers to the maximum observed NDVI and was calculated as the average of the five largest observed values. NDVI is the specific NDVI for a given pixel at a given time. Small differences between MODIS-derived $f_{\mathrm{c}}$ and the Meteosat-derived $f_{\mathrm{c}}$ used in the ALEXI processing stream may have a small impact on estimates of relative error between the three soil moisture products.

\subsubsection{Calculation of anomalies}

Weighted sums of surface and root zone soil moisture were generated for LPRM and Noah using the NDVI $f_{\mathrm{c}}$ and the method described in the previous Sect. 2.3.3. These depthmatched datasets were then used in the anomaly analysis. Two categories of anomalies were produced for this study: time series anomalies averaged over the area of interest ( 40.625 to $48.125^{\circ}$ E, -3.1255 to $9.375^{\circ} \mathrm{N}$; Fig. 1 ), and spatially distributed anomalies for all of East Africa in hydrologic year 2010-2011. The area of interest was selected to capture the area of maximum drought intensity, as identified through our own analyses and independent reports of the drought. All anomalies were calculated relative to the pre-drought baseline, 2003-2010. The ALEXI model was not included in the anomaly analysis, because the dataset for East Africa only dates back to 2007 due to limitations on the LSA SAF product archive extent.

\subsubsection{TCA and TCA-based data merging}

Triple collocation analysis (TCA) is a method that can be used to estimate the relative error variance associated with three collocated datasets, provided that the datasets are mutually linear and have independent error characteristics (Janssen et al., 2007; Zwieback et al., 2012). TCA is a powerful technique but only produces meaningful results if each dataset is measuring the same physical parameter (and are therefore mutually linear). To ensure that independent datasets were, indeed, appropriate for TCA, crosscorrelations of the products were calculated. Pixels with very low cross-correlations $(r<0.2)$ were interpreted as nonanalogous and were excluded from the TCA. All datasets were converted to a single reference climatology to account for variations in mean and standard deviation, following the methods of Hain et al. (2011); in this case, Noah was chosen to be the reference dataset for the TCA calculations, but the choice of reference does not affect the results of the analysis.

As part of the data normalization process, a seasonal mean $(\mu)$ and standard deviation $(\sigma)$ were computed for each eightday composite soil moisture estimate $(\theta)$ of each dataset. The seasonal mean and standard deviation were calculated for the years 2007-2010 using a 24-day centered window (one composite-week on either side of the composite of interest) and used to convert the ALEXI and LPRM soil moisture estimates into Noah climatology as outlined in Eqs. (7) and (8):

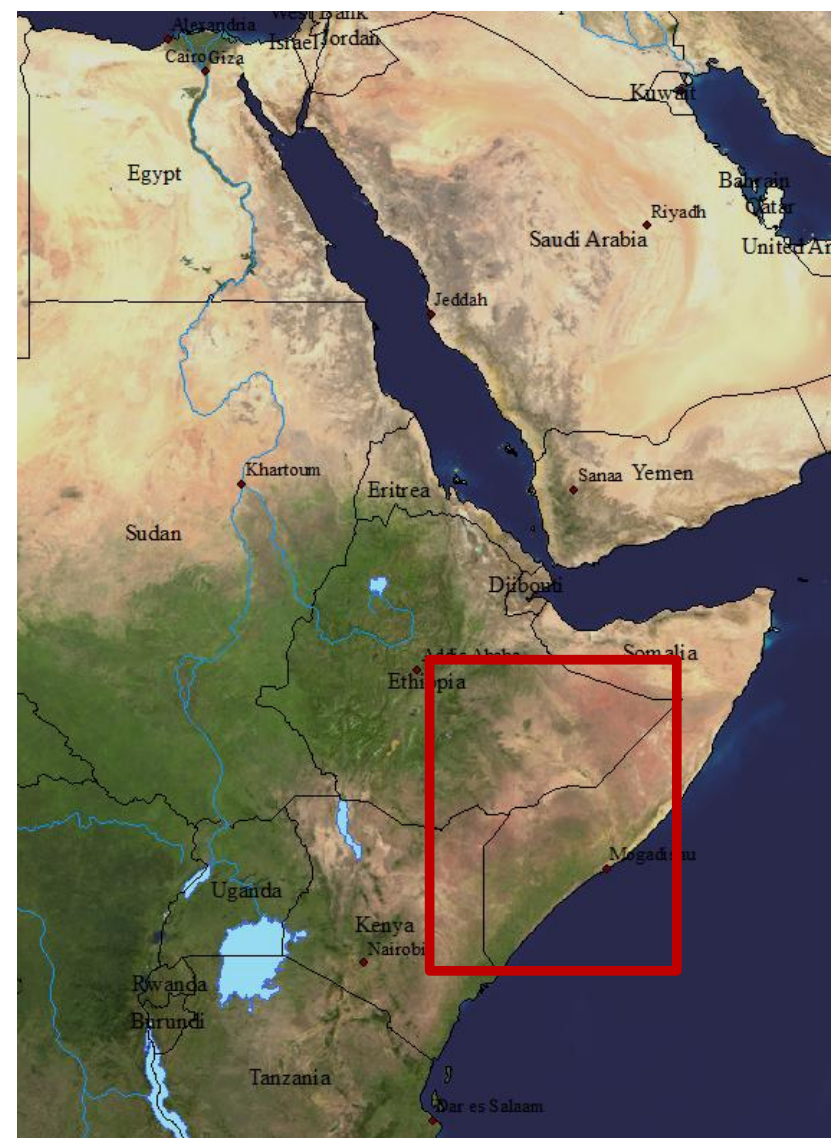

Fig. 1. Selected area of interest within the Horn of Africa (40.625, $48.125,-3.125,9.375)$ [W, E, S, N].

$$
\begin{aligned}
& \theta_{\mathrm{LPRM}}^{\prime}=\mu_{\text {Noah }}+\left(\theta_{\text {LPRM }}-\mu_{\text {LPRM }}\right)\left(\frac{\sigma_{\text {Noah }}}{\sigma_{\text {LPRM }}}\right) \\
& \theta_{\text {ALEXI }}^{\prime}=\mu_{\text {Noah }}+\left(\theta_{\text {ALEXI }}-\mu_{\text {ALEXI }}\right)\left(\frac{\sigma_{\text {Noah }}}{\sigma_{\text {ALEXI }}}\right) .
\end{aligned}
$$

Following the conversion to a single climatology, the normalized seasonal composites $\left(\theta^{\prime}\right)$ were linearly rescaled and used as input for TCA as described in Eq. (9) through Eq. (10). A full discussion of these methods can be found in Stoffelen (1998). Each pixel from each dataset was analyzed over the 2007-2010 time period to calculate TC values $\left(\varepsilon^{2}\right)$ :

$$
\begin{aligned}
\varepsilon_{\text {Noah }}^{2} & =\left\langle\left(\theta_{\text {Noah }}-\theta_{\text {LPRM }}^{\prime \prime}\right)\left(\theta_{\text {Noah }}-\theta_{\text {ALEXI }}^{\prime \prime}\right)\right\rangle \\
\varepsilon_{\text {LPRM }}^{2} & =\left\langle\left(\theta_{\text {LPRM }}^{\prime \prime}-\theta_{\text {Noah }}\right)\left(\theta_{\text {LPRM }}^{\prime \prime}-\theta_{\text {ALEXI }}^{\prime \prime}\right)\right\rangle \\
\varepsilon_{\text {ALEXI }}^{2} & =\left\langle\left(\theta_{\text {ALEXI }}^{\prime \prime}-\theta_{\text {LPRM }}^{\prime \prime}\right)\left(\theta_{\text {ALEXI }}^{\prime \prime}-\theta_{\text {Noah }}\right)\right\rangle
\end{aligned}
$$

where $\theta^{\prime \prime}$ represents the rescaled seasonal composites and brackets indicate a temporal average taken over the study period 2007-2010.

In areas above the correlation threshold set for the TCA, TC error values were used as an objective measure for soil moisture data merging. A least squares approach was used 


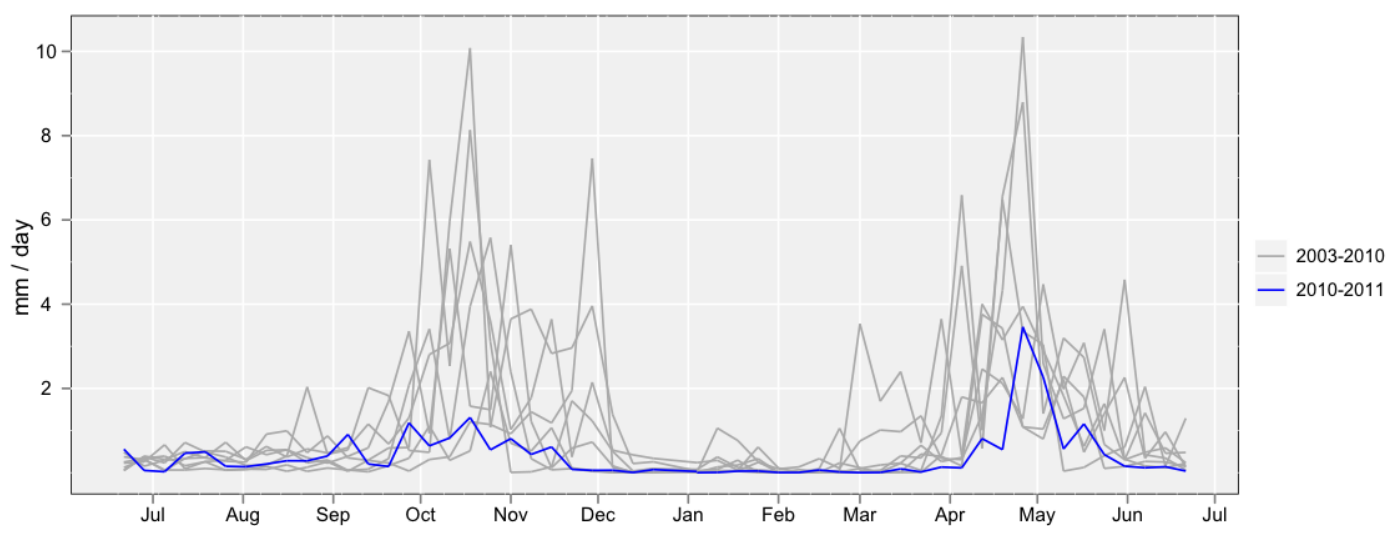

Fig. 2. TMPA 3B42 precipitation estimates from 2003-2011: blue $=2010-2011$; gray $=$ all other years.

to derive the weights for each product following the methods of Yilmaz et al. (2012). In order to produce an unbiased merged product, the sum of the weights of all products was constrained to one $\left(w_{x}+w_{y}+w_{z}=1\right)$. The cost function $(J)$ to be minimized in this case is the error variance of the merged product obtained from the least squares-based merging method that depends on the TCA-based errors. The cost function changes depending on the number of available soil moisture datasets for a given time and location. If only two datasets are available at a given pixel, the cost function is

$J=\varepsilon_{m}^{2}=w_{x} \varepsilon_{x}^{2}+\left(1-w_{x}\right) \varepsilon_{y}^{2}$.

If all three datasets are available, the cost function becomes

$J=\varepsilon_{m}^{2}=w_{x} \varepsilon_{x}^{2}+\left(1-w_{x}-w_{z}\right) \varepsilon_{y}^{2}+w_{z} \varepsilon_{z}^{2}$,

and if only one dataset is available, it is given the full weight. Applying the least squares approach to the cost functions in Eqs. (12) and (13) yields the following weights.

For two available datasets scenario

$w_{x}=\frac{\varepsilon_{y}^{2}}{\varepsilon_{x}^{2}+\varepsilon_{y}^{2}}$

$w_{y}=\frac{\varepsilon_{x}^{2}}{\varepsilon_{x}^{2}+\varepsilon_{y}^{2}}$.

For three available datasets scenario

$$
\begin{aligned}
& w_{x}=\frac{\varepsilon_{y}^{2} \varepsilon_{z}^{2}}{\varepsilon_{x}^{2} \varepsilon_{y}^{2}+\varepsilon_{x}^{2} \varepsilon_{z}^{2}+\varepsilon_{y}^{2} \varepsilon_{z}^{2}} \\
& w_{y}=\frac{\varepsilon_{x}^{2} \varepsilon_{z}^{2}}{\varepsilon_{x}^{2} \varepsilon_{y}^{2}+\varepsilon_{x}^{2} \varepsilon_{z}^{2}+\varepsilon_{y}^{2} \varepsilon_{z}^{2}} \\
& w_{z}=\frac{\varepsilon_{x}^{2} \varepsilon_{y}^{2}}{\varepsilon_{x}^{2} \varepsilon_{y}^{2}+\varepsilon_{x}^{2} \varepsilon_{z}^{2}+\varepsilon_{y}^{2} \varepsilon_{z}^{2}} .
\end{aligned}
$$

Equations (14)-(18) were used to produce a weighting map for each product in the domain of the TC analysis. Note that these weights are stationary provided that the number of datasets with available measurements remains constant.

In areas below the correlation threshold set for the TCA, no TC error values were produced; however, that does not mean that no useable data are available for the weighting map. For the case in which a significant correlation was observed between two of the methods in an area that was screened out of the TCA, an equal weight was assigned to each of the correlated methods.

\section{Results and discussion}

\subsection{Anomaly analysis}

TMPA precipitation measurements from June 2003 to June 2011 were used to compare the magnitude and duration of the 2010-2011 seasonal rains with those of the previous seven years (Fig. 2). The precipitation data show a near complete failure of the October-December rains as well as weak April-June rains. In fact, FEWS NET determined that the total anomaly in precipitation during the 2010-2011 rainy seasons was the most severe in the last $50 \mathrm{yr}$ for parts of Kenya and Ethiopia (USAID FEWS NET, 2011). The lack of precipitation is evident in modeled and remotely sensed estimates of soil moisture, NDVI, and terrestrial water storage (Fig. 3). For each of these variables, the 2010-2011 drought was the most severe or close to the most severe negative anomaly in magnitude and duration recorded during the period of analysis. The drought is unique in that it was a twoseason drought of comparable magnitude to previous drying events of shorter duration.

The datasets displayed in Fig. 3 represent the 2010-2011 droughts in similar but not identical ways. Soil moisture anomalies (LPRM and Noah) have negative trends from the very beginning of the negative anomaly in precipitation (October 2010), but they persist beyond the end of each failed rainy season. This is to be expected, as soil moisture anomalies reflect cumulative precipitation anomalies and are known 


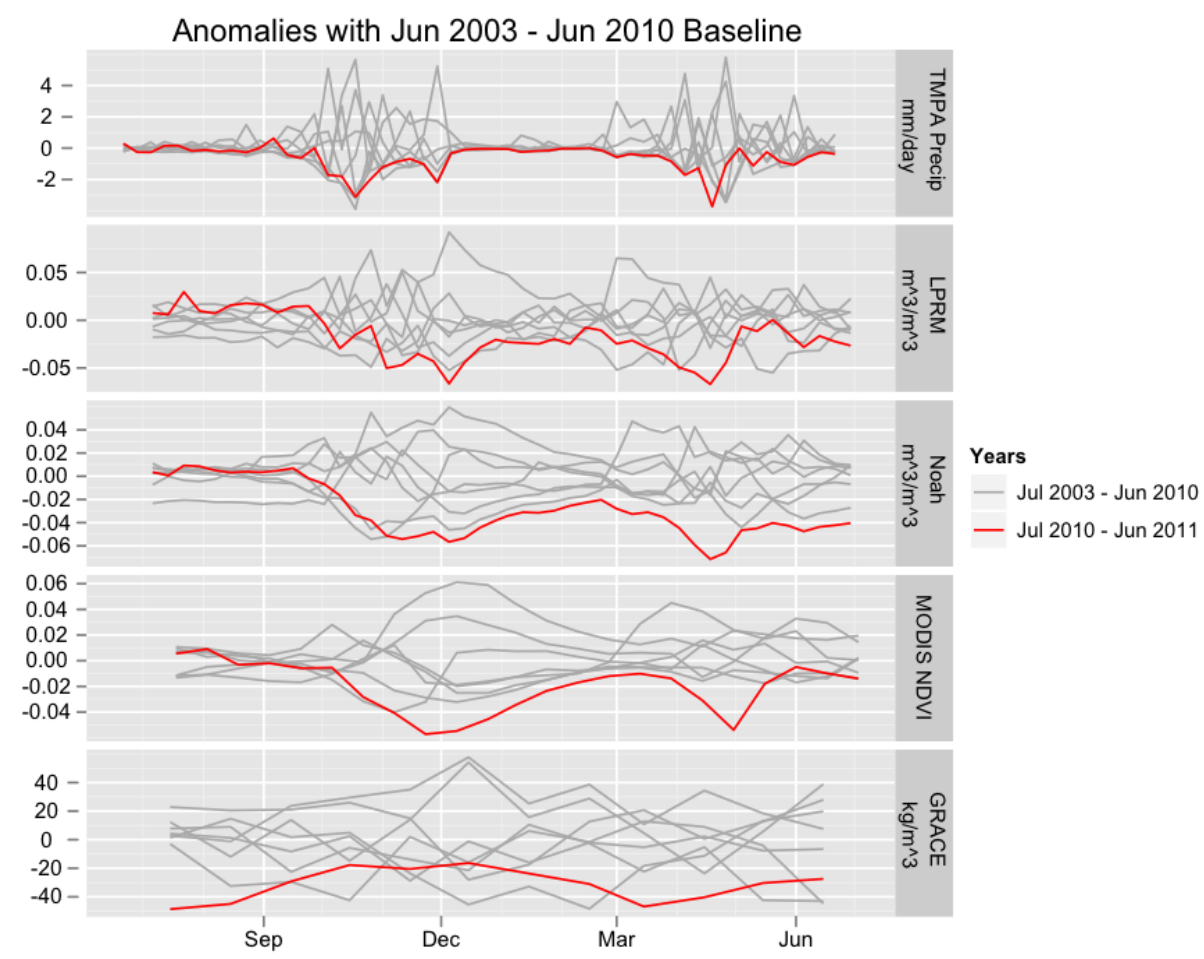

Fig. 3. Anomaly analysis of TMPA precipitation, LPRM and Noah soil moisture estimates, MODIS NDVI and GRACE terrestrial water storage using a January 2003 to June 2010 baseline.

to provide memory in the climate and hydrological system. In the period between the 2010 short rains and the 2011 long rains, TMPA anomalies return to near zero - true almost by definition for the period between rainy seasons in this region - and LPRM, which is dominated by surface soil moisture variability, notwithstanding the $f_{\mathrm{c}}$ filter, nearly returns to a zero anomaly as well. Noah soil moisture and MODIS NDVI anomalies, both of which reflect dry conditions in the root zone, remain negative between rainy seasons, illustrating how the agricultural drought carried over from the failed short rains to the beginning of the long rainy season. A snapshot of NDVI or Noah root zone soil moisture anomalies taken in March 2011, then, would indicate that the land had a moisture deficit going into the planting season, where a snapshot of surface soil moisture or precipitation would not.

GRACE offers an entirely different perspective on the drought. Interestingly, there was a negative anomaly in terrestrial water storage even at the "onset" of the 2010-2011 drought. Indeed, GRACE retrievals indicate that total water storage in the area of interest has declined relatively steadily since 2007 (data not shown). The relevance of this multiyear decline in total water storage to drought impacts in 20102011 has yet to be investigated.

\subsection{Spatial anomalies}

Figure 4 illustrates the spatial distribution of soil moisture anomalies in the short and the long rainy seasons. LPRM,
ALEXI and Noah soil moisture anomalies all reflect that the failure of the short rains (late September to December) was greatest in southern Somalia, Kenya and east Ethiopia while the long rain failures (April to July) extended further into Kenya, Ethiopia and Sudan. In general the soil moisture estimates agree relatively well on the location and magnitude of the drought, but there is some discrepancy in the observed spatial extent, as Noah detects a more intense drying in central Sudan during the long rains than either of the satellitebased methods.

Figure 5 shows temporal cross-correlation of rescaled soil moisture anomalies between ALEXI and Noah (Fig. 5a), LPRM and Noah (Fig. 5b), and LPRM and ALEXI (Fig. 5c) for the period 2007 to 2010. The difference in crosscorrelations is displayed in Fig. 6. For regions missing only one dataset, the cross-correlation between the remaining two methods is displayed, notwithstanding edge effects due to differences in coastal definition. Previous work in the US (Hain et al., 2011) has indicated that ALEXI and LPRM soil moisture retrievals perform optimally in complementary regions due to strengths and limitations of each retrieval technique. Passive microwave soil moisture retrievals, including LPRM, are inherently limited to the top $1-2 \mathrm{~cm}$ of the soil column. Use of the exponential filter softens this limitation, assuming a correlation between surface and root-zone soil moisture, and can capture the influence of deeper soil moisture to some extent, but the LPRM soil moisture estimate is 

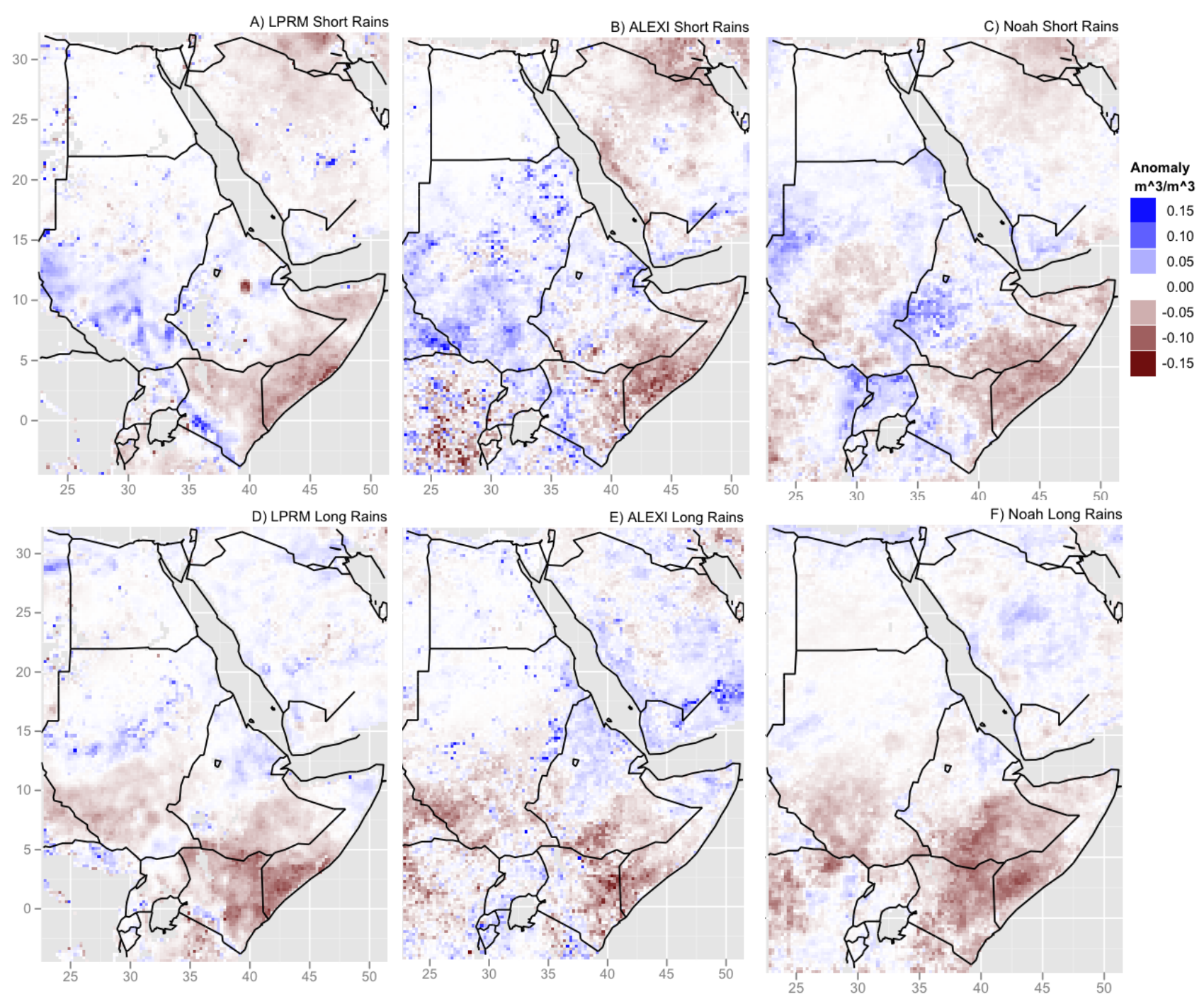

Fig. 4. Seasonal anomalies averaged over the 2010 short rains (A-C) and 2011 long rains (D-F) for LPRM (A, D), ALEXI (B, E) and Noah $(\mathbf{C}, \mathbf{F})$. The short rains are defined as the period from 12 September-1 December, while the long rains span 28 March -30 June.

still highly sensitive to near-surface soil moisture variability, which makes it most appropriate in sparsely vegetated regions where vertical support of soil moisture is relatively small. In addition, attenuation of the microwave signal in areas of dense vegetation disrupts the retrieval of soil moisture measurements, potentially to the point of being unusable (Njoku et al., 2004; Owe et al., 2008). To ensure that the observed patterns of cross-correlation are a result of the information present in the LPRM soil moisture estimates, and not a result of the exponential filter applied to the original data, a series of sensitivity analyses were conducted. When the cross-correlations displayed in Fig. 5 were reproduced using the LPRM data without the addition of the exponential filter, the spatial patterns of correlation remained unchanged and the magnitude of correlation changed only marginally for a limited number of areas (results not shown). The similarity of the cross-correlations with and without the exponential filter applied to the LPRM data underscores the sensitivity of the microwave soil moisture estimates to near-surface soil moisture variability.

The ALEXI thermal infrared model, in contrast, obtains its measurements based on radiometric temperature partitioned between the soil and vegetation. This means that, while the physical depth of measurement may change as a function of vegetation, the performance is not expected to deteriorate with increasing vegetation cover, as found by Hain et al. (2011). Indeed, the fact that the thermally based soil moisture estimate integrates the effects of surface evaporation and plant transpiration makes it particularly valuable in densely vegetated regions, where root zone soil moisture variability can be significant. 

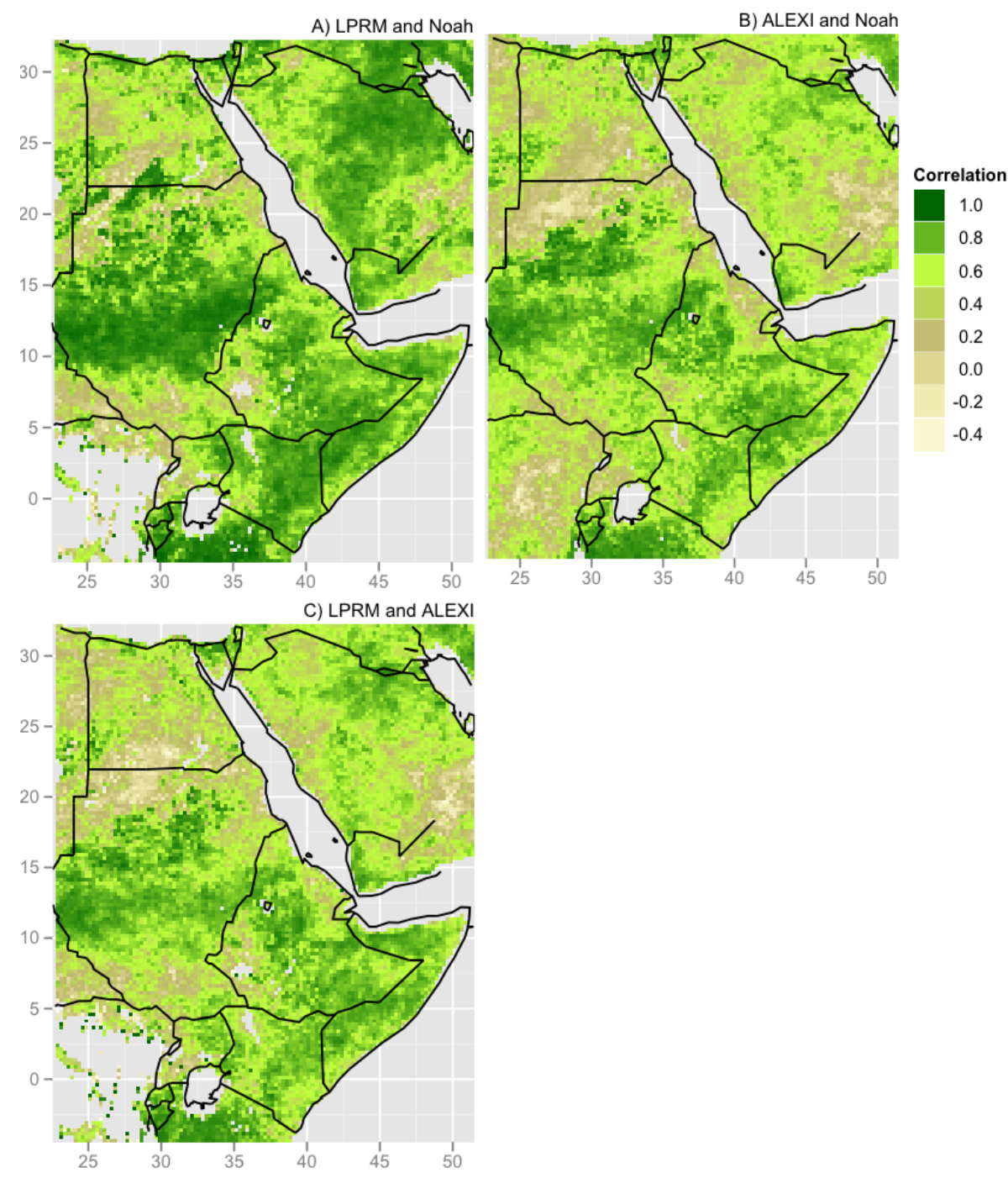

Fig. 5. Temporal cross-correlation of rescaled soil moisture anomalies for January 2007-June 2010 computed between (A) LPRM and Noah, (B) ALEXI and Noah, and (C) ALEXI and LPRM.

Figures 5 and 6 allow us to explore this pattern, first using Noah, then ALEXI as a point of reference. Over the majority of extremely arid regions (e.g., Egypt, northern Sudan and portions of Saudi Arabia and the Horn), neither LPRM nor ALEXI clearly correlates more strongly with Noah. Similarly, Fig. 6b demonstrates that, when ALEXI is used as the reference dataset, neither LPRM nor Noah displays dominant correlation. Over semi-arid regions (e.g., central Sudan, portions of southern Ethiopia, Kenya and Somalia), LPRM correlates more strongly with Noah than does ALEXI, largely because LPRM errors are low for sparse vegetation cover while ALEXI errors are moderate across all vegetation conditions. This relation is highlighted in Fig. $6 \mathrm{~b}$ by the comparable correlations of LPRM and Noah with ALEXI in semi-arid regions. Some of the difference in perceived skill between ALEXI and LPRM/Noah in such regions may be related to the shorter repeat cycles of the microwave sensors and LSM output as compared with the thermal infrared method. Over areas of dense vegetation (e.g., western Ethiopia and the Congo Basin), LPRM correlates poorly with both Noah and ALEXI. This is in part due to interference from vegetation and in part due to the fact that LPRM soil moisture estimates, even when adjusted with an $f_{\mathrm{c}}$ filter, are dominated by near surface rather than root zone variability.

These spatial patterns can be summarized by plotting the difference between LPRM and ALEXI correlation with Noah as a function of fractional vegetation cover (Fig. 6c and d). In this application, the crossing point at which the sensors are approximately equally correlated with Noah is at an $f_{\mathrm{c}}$ of 0.65 . Above this threshold, ALEXI correlates more strongly with Noah, while below it LPRM correlates more strongly. The greatest divergence of the satellite-based soil moisture estimates is in the extremes of vegetation density 

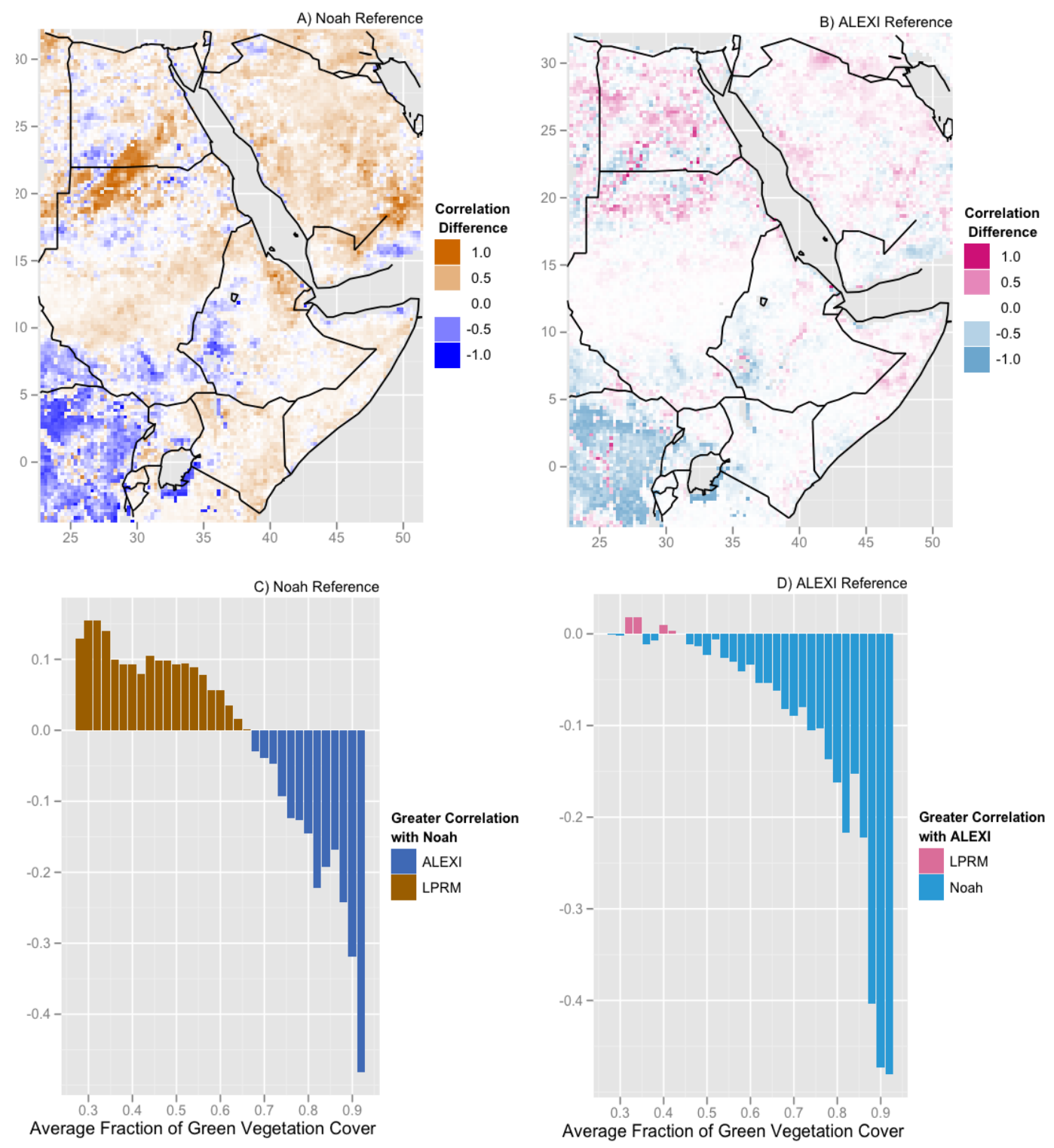

Fig. 6. Anomaly correlation difference using Noah $(\mathbf{A}, \mathbf{C})$ and ALEXI $(\mathbf{B}, \mathbf{D})$ as reference datasets. Areas shaded in brown or pink represent a greater correlation between LPRM and the reference dataset. (A) and (B) show the spatial distribution of correlation differences, while (C) and (D) show correlation differences as a function of the average fraction of green vegetation during the rainy seasons.

$\left(f_{c}<0.35\right.$ and $\left.f_{\mathrm{c}}>0.8\right)$. Using ALEXI as the reference dataset reinforces these relations. At low to moderate vegetation density LPRM and Noah are comparably correlated with ALEXI, while at moderate to high vegetation density Noah correlates more strongly with ALEXI than does LPRM.

\subsection{Triple collocation analysis and data merging}

TCA was employed to quantify relative agreement across the three soil moisture datasets and to provide an objective basis for data merging. The chosen datasets display high cross-correlations across the majority of the domain (indicating highly linear relationships between products) and are therefore suitable for a triple collocation analysis framework, assuming that the products have independent error characteristics. To evaluate whether the calibration of the exponential filter violates this assumption, the TCA estimates obtained using the exponential filter with a calibrated characteristic time were compared to those obtained using exponential filters with uniform characteristic times set at 8,16 and 24 days. The results were TCA values that differed only marginally in magnitude and not at all in structure (results not shown), indicating that the use of a calibrated exponential filter does not violate the assumption of independent error characteristics required for triple collocation analysis. The final assumption introduced during data processing to be evaluated 

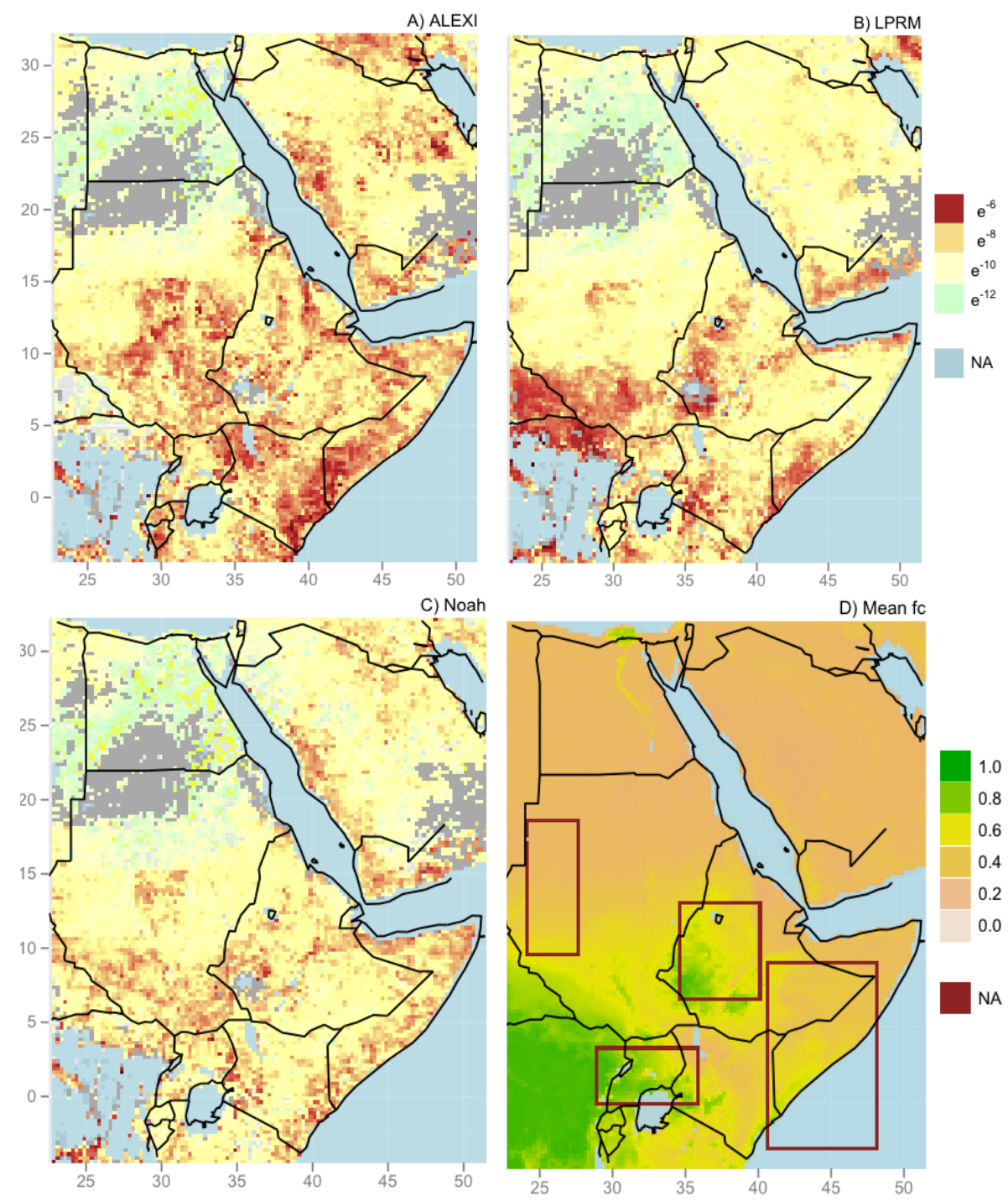

Fig. 7. The variance of the triple collocation analysis-based errors in $\left(\mathrm{m}^{3} \mathrm{~m}^{-3}\right)^{2}$ for each product juxtaposed with the annual average fraction of green vegetation cover. (A) ALEXI TCA, (B) LPRM TCA, (C) Noah TCA, (D) mean fraction of green vegetation cover over the period 2007 to 2011. Gray areas in panels (A)-(C) indicate regions below the correlation threshold for the TC analysis $(r<0.2)$. Red boundaries in panel (D) indicate bounding boxes for the analysis in Tables 1-4.

is the vertical support consistency of the three soil moisture datasets, an issue extensively discussed in Yilmaz et al. (2012). In their paper, Yilmaz et al. (2012) show that the applicability of TCA using products that have different vertical support information depends on the linear relationship between soil moisture at different soil depths (i.e., surface, vegetation-adjusted soil moisture, or root-zone). The depth variations will pose a problem if they manifest themselves in a nonlinear or a hysteric relationship; instead, if the relationship is linear, then it fits into the TCA framework. Therefore, the impact of vertical inconsistencies will depend on the linear relation between the soil moisture values of different layers. Similar to what Yilmaz et al. (2012) have found over US, we found a very high linear relation between the representative soil depths of the products (results not shown); hence, we expect the vertical support inconsistencies are effectively handled via the linear rescaling performed in TCA equations. TCA was not applied, however, in some arid regions both because of the low cross-correlations in these regions and because drought monitoring in these persistently dry regions is not a practical priority. These arid regions were masked out of TCA on the basis of their low correlation coefficient between datasets (Fig. 7). It should be noted, however, that the TCA results reported in this paper are based on a somewhat limited time series due to data availability, and that, as additional data become available, they may be incorporated into the analytical framework outlined in this paper. Given a longer time series, the TC error values would be 

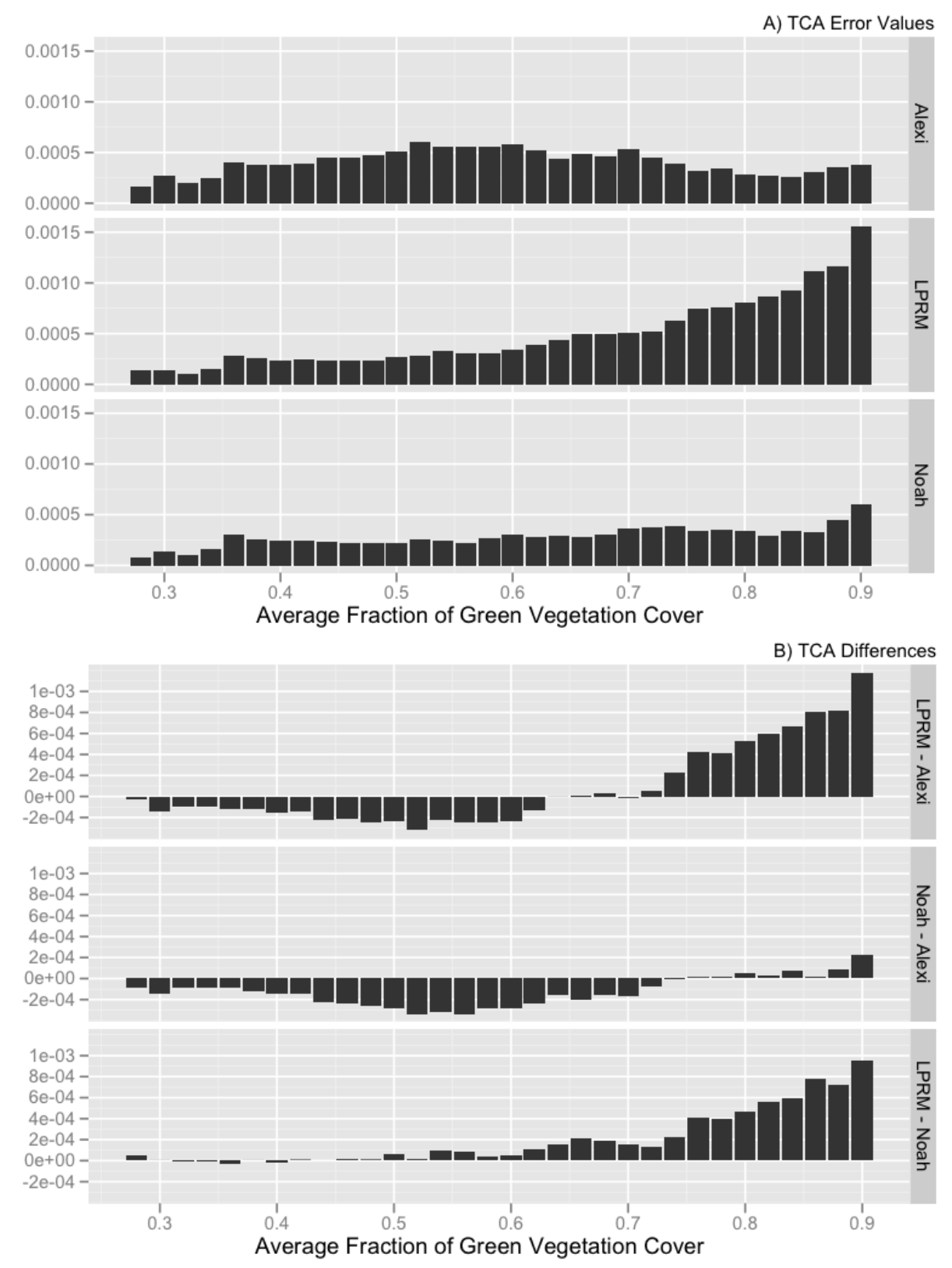

Fig. 8. The variance of the triple collocation analysis-based errors in $\left(\mathrm{m}^{3} \mathrm{~m}^{-3}\right)^{2}$ binned as a function of average fraction of green vegetation cover during the rainy season, showing (A) TCA error values for each SM retrieval technique, and (B) differences in TCA between retrieval techniques.

expected to vary seasonally. For example, the TC error values during the rainy season would be expected to be larger simply because the magnitude of soil moisture during rainy events is larger. For this study, however, the TC error values were assumed constant in time due to the short time series of available data.

As with the correlations between products, the spatial variability of the TC error values for each product was evaluated as a function of the fraction of green vegetation (Figs. 7 and 8). LPRM has a clear dependence on the fraction of green vegetation cover, with a marked increase in TC errors above $f_{\mathrm{c}}=0.75$. As a passive microwave-based sensor, it is expected that the accuracy of LPRM soil moisture retrievals would decrease over areas of dense vegetation (Hain et al., 2011). The poor performance of LPRM in densely vegetated areas is reflected in the TC error values displayed in Fig. 7, especially over the Congo Basin. In these regions, valid LPRM soil moisture retrievals are often not available, and are of relatively low accuracy when they are available. 

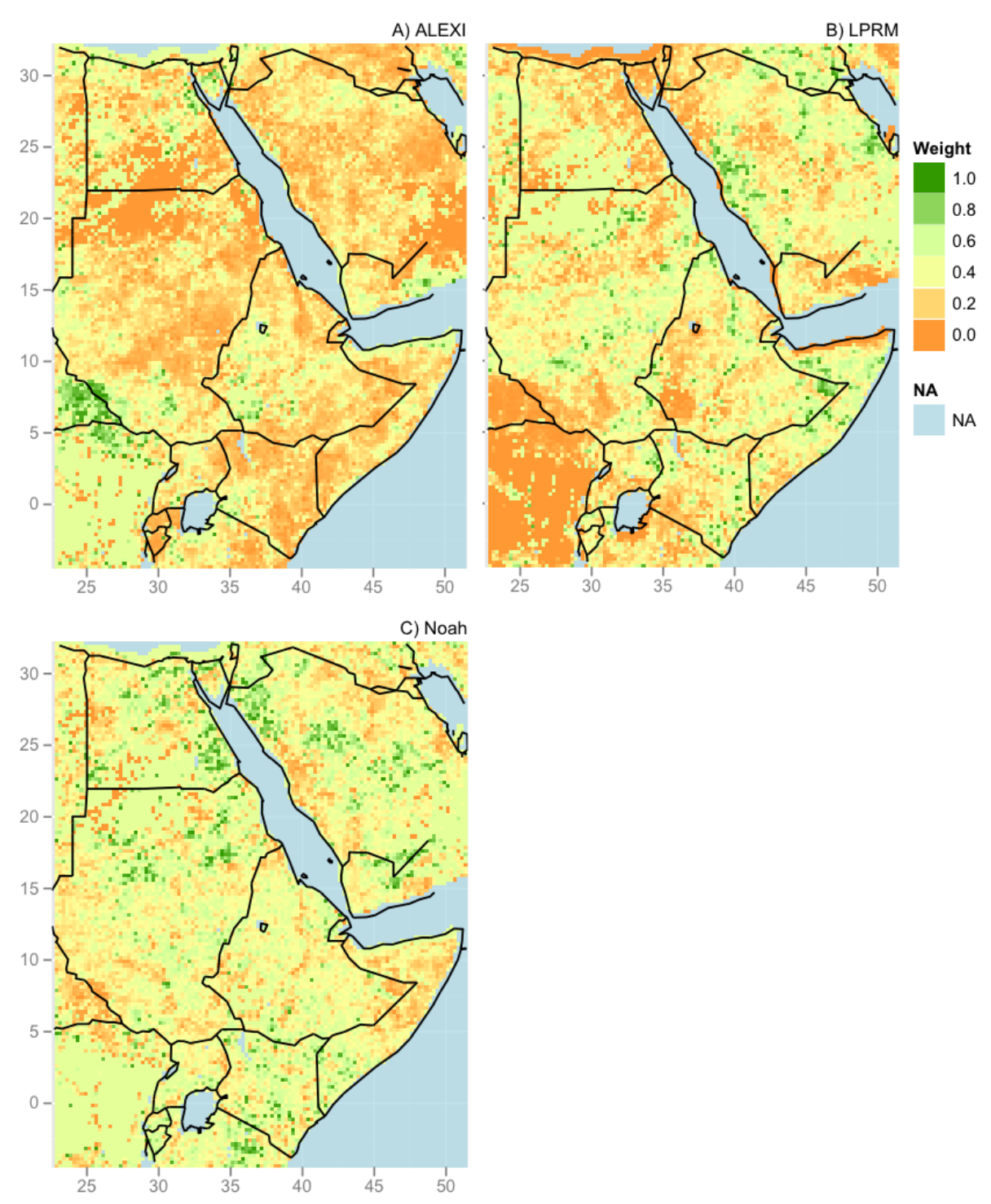

Fig. 9. TCA-based weight map for the case in which data are available from all products for (A) ALEXI, (B) LPRM and (C) Noah. The sum of weights per location adds to unity.

ALEXI and Noah have a less pronounced dependence on the fraction of green vegetation, but in general Noah maintains the constant TC error values across all $f_{\mathrm{c}}$, while the TC error values of ALEXI decrease above moderate $f_{\mathrm{c}}$. These trends are further confirmed in Fig. 8b, showing the relative TC errors between retrieval techniques. LPRM has the highest TC over high mean fraction of vegetation cover $\left(f_{\mathrm{c}}>0.70\right)$, while for areas with a low to moderate fraction of vegetation cover $\left(f_{\mathrm{c}}<0.70\right)$ ALEXI displays higher TC error values than those of Noah or LPRM.

When considering the TC error values from a data merging perspective, higher relative TC error values correspond to lower merging weights (see Eqs. 14-18). In an operational setting, these weights would be expected to change with time as the TC error values vary. However, as previously discussed, the assumption of TC error values constant in time leads to weights that are also constant in time. Owing to the heterogeneity of fractional vegetation and the complementary retrieval techniques, LPRM and ALEXI received low merging weights in offsetting regions, while Noah received fairly constant weights across the domain. This relationship is best illustrated by selecting a number of specific regions to analyze. For the purposes of this study, four regions for which drought may be of concern but which display markedly different vegetation cover were chosen: the Ethiopian Highlands, the Horn of Africa, northern Lake Victoria and Darfur (see Fig. 7). As expected, in the areas dominated by low fractional vegetation and an arid climate (Darfur and the Horn of Africa), LPRM and Noah received a higher merging weight and in general displayed lower TC 

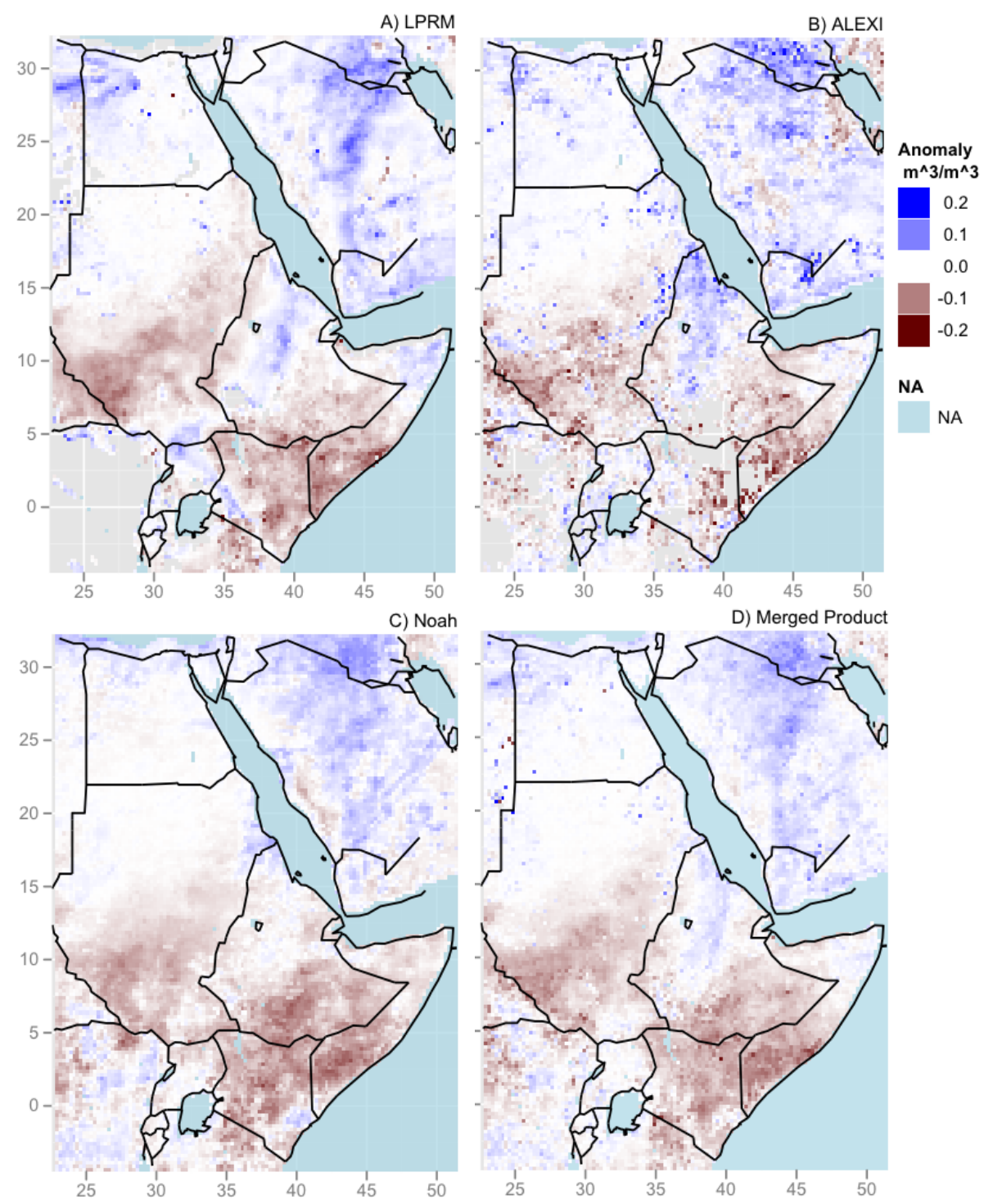

Fig. 10. Individual and merged product anomaly maps for an 8-day period during the 2011 long rainy season (28 April-6 May). (A) LPRM, (B) ALEXI, (C) Noah, (D) Merged product.

error values than ALEXI (Tables 1-4). However, over moderate to dense fractional vegetation, the performance of LPRM degraded (as TC error values increased), while ALEXI and Noah on average had lower TC error values and therefore received a higher merging weight.

Bearing in mind the predominantly arid conditions of the study region, these results are also consistent with the correlation analysis (Fig. 5 and Table 5), which indicates that Noah has the highest cross-correlations and LPRM crosscorrelations are better than the cross-correlations of ALEXI. However, the majority of the cross-correlation differences are only marginal, especially the difference between the crosscorrelations of Noah and ALEXI, implying the weight differences we find here are only due to small differences that exist in the cross-correlations. Here the weights do not imply any relation with the absolute magnitude of the errors, but rather only give information about the relative magnitudes of the errors regardless of the error differences.

The performance of the merged product was compared to each individual method in Fig. 10, which compares estimates of soil moisture during an 8-day period of the long rains in 2011. The merged product achieves a more complete spatial coverage than either of the satellite methods while reflecting a consensus location and magnitude anomaly pattern. The year-long progression of the 2010-2011 drought is depicted in Fig. 11, which displays the monthly anomalies of the merged product for July 2010-June 2011. This figure highlights the spatial evolution of the two-season drought as captured by the merged product. 

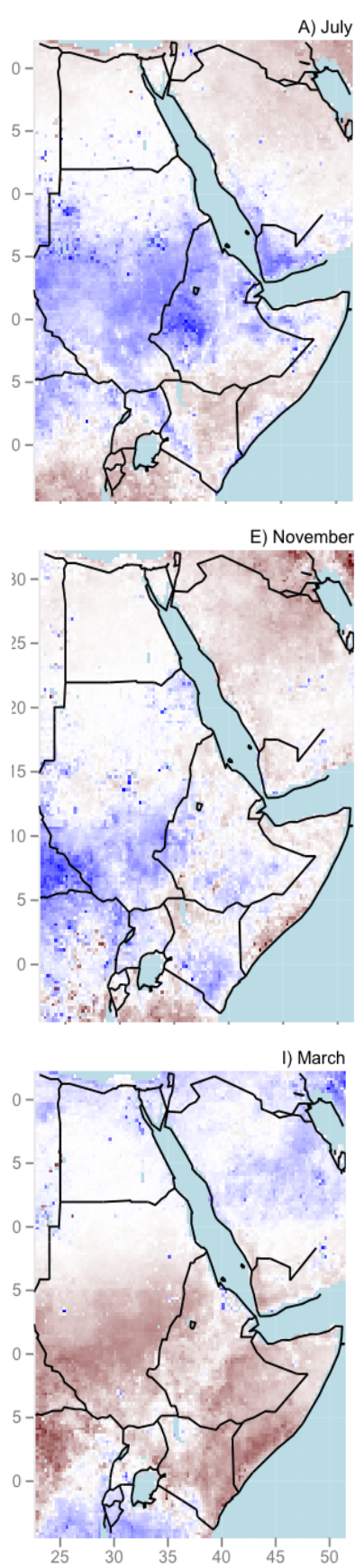
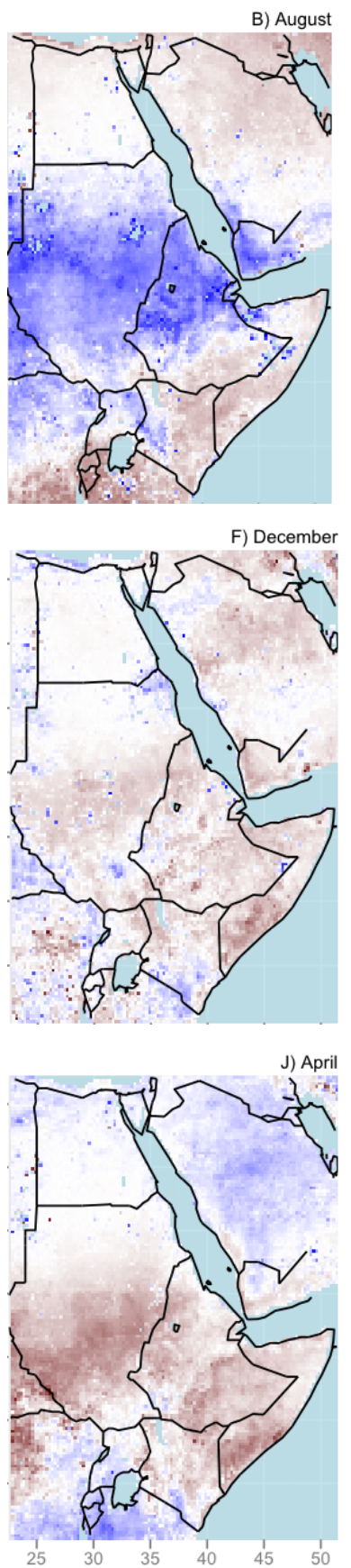
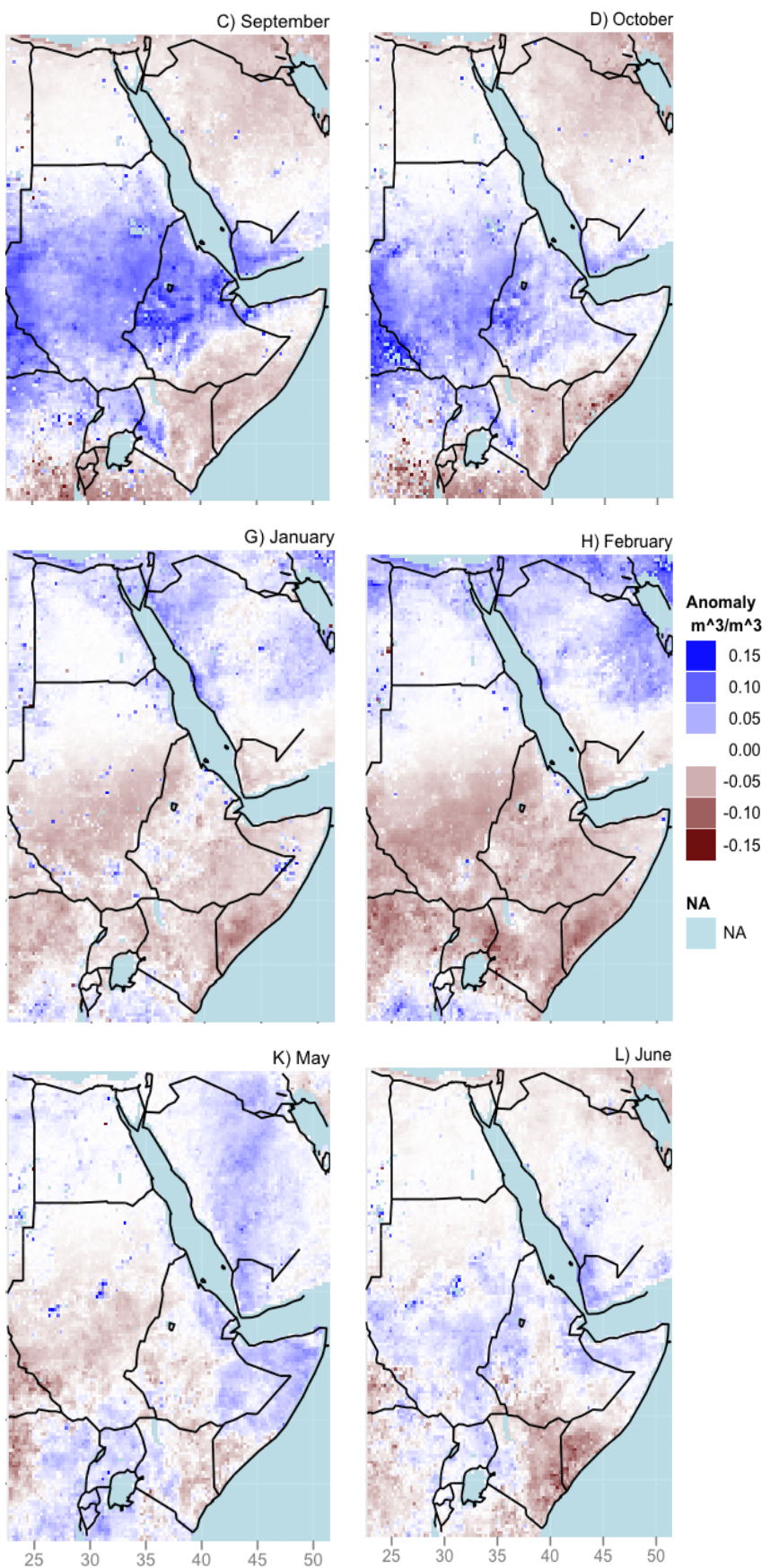

Fig. 11. Monthly anomaly maps of the progression of the 2010-2011 drought using the merged product. July-December 2010 (A-F) and January-June 2011 (G-L).

Importantly, the merged product and all three independent products generally agree on the seasonality and general patterns of interannual variability in soil moisture in the drought-affected region (Fig. 12). This suggests that the independent products are capturing sufficiently similar processes at seasonal and interannual timescales, and it indicates that, within the drought-affected region, the merged product provides a spatially complete, consensus-derived drought monitor that is not overly influenced by discrepancies between datasets. This point is reinforced by the fact that there is near total agreement in the rank order soil moisture deficit conditions for long and short rainy seasons across LPRM, ALEXI, Noah, and the merged product (Table 6). In all cases, the 2010 short rains and 2011 long rains are identified as the most anomalously dry rainy seasons in the 5-yr record. This consistency in results offers some confidence that the 
Table 1. Average merging weight and TC error values for the Ethiopian Highlands.

\begin{tabular}{lcc}
\hline \multicolumn{3}{c}{$\begin{array}{c}\text { Ethiopian Highlands } \\
(34.59,40.21,6.86,13.53)[\mathrm{W}, \mathrm{E}, \mathrm{S}, \mathrm{N}]\end{array}$} \\
\hline Retrieval & $\begin{array}{c}\text { Average TCA } \\
\text { value } \\
{\left[\left(\mathrm{m}^{3} \mathrm{~m}^{-3}\right)^{2}\right]}\end{array}$ & $\begin{array}{c}\text { Average } \\
\text { merging } \\
\text { weight }\end{array}$ \\
\hline LPRM & $4.312 \times 10^{-4}$ & 0.283 \\
ALEXI & $3.914 \times 10^{-4}$ & 0.331 \\
Noah & $2.822 \times 10^{-4}$ & 0.385 \\
\hline
\end{tabular}

merged product for the drought region is informed by consensus between all three products and is not disregarding one product in favor of consensus between the other two. The rainy season rankings of these soil moisture products is also broadly consistent with rankings derived from vegetation index anomalies and GRACE water storage anomalies (see Fig. 3). Relatively small discrepancies between products - for example, the relatively slow dry-down in ALEXI observed in 2009 and 2011 (Fig. 12) - are interesting in their own right and are the subject of further study. But they do not strongly influence the seasonal rankings.

\section{Conclusions}

Remote sensing and physically based models are critically important methods for monitoring drought in areas with limited in situ observation networks, particularly for countries with food security concerns. As shown in this study, remotely sensed observations are valuable for their spatial and temporal continuity as well as for their diversity - satellitederived observations of precipitation, soil moisture, vegetation condition and terrestrial water storage offer a range of information on meteorological, agricultural, and hydrological drought over space and time. An anomaly analysis of satellite- and model-based drought indicators demonstrated that the 2010-2011 drought stands out as an extreme event according to all measures included in this study. But different data records provide different perspectives on the onset and progression of the drought. TMPA and LPRM capture rapid-response anomalies associated with the failure of rains in each rainy season, while ALEXI and Noah track the evolution of the drought as it deepened from 2010 to 2011, and GRACE captures the fact that the drought occurred against a background of a multi-year deficit in the regional water balance. This diversity of information is valuable for tracking the progression and severity of a drought and for anticipating the impacts that an emerging drought may have on ecological and human systems.

In addition to providing observations that capture diverse drought-related processes across time and space, earth
Table 2. Average merging weight and TC error values for Darfur.

\begin{tabular}{lcc}
\hline \multicolumn{3}{c}{$\begin{array}{c}\text { Darfur } \\
(23.89,27.78,9.82,19.09)\end{array}$} \\
\hline Retrieval & $\begin{array}{c}\text { Average TCA } \\
\text { value } \\
{\left[\left(\mathrm{m}^{3} \mathrm{~m}^{-3}\right)^{2}\right]}\end{array}$ & $\begin{array}{c}\text { Average } \\
\text { merging } \\
\text { weight }\end{array}$ \\
\hline LPRM & $1.107 \times 10^{-4}$ & 0.351 \\
ALEXI & $1.561 \times 10^{-4}$ & 0.264 \\
Noah & $1.134 \times 10^{-4}$ & 0.384 \\
\hline
\end{tabular}

Table 3. Average merging weight and TC error values for the Horn of Africa.

\begin{tabular}{|c|c|c|}
\hline \multicolumn{3}{|c|}{$\begin{array}{c}\text { Horn of Africa } \\
(40.62,48.12,-3.12,9.37)[\mathrm{W}, \mathrm{E}, \mathrm{S}, \mathrm{N}]\end{array}$} \\
\hline Retrieval & $\begin{array}{c}\text { Average TCA } \\
\text { value } \\
{\left[\left(\mathrm{m}^{3} \mathrm{~m}^{-3}\right)^{2}\right]}\end{array}$ & $\begin{array}{l}\text { Average } \\
\text { merging } \\
\text { weight }\end{array}$ \\
\hline LPRM & $3.023 \times 10^{-4}$ & 0.401 \\
\hline ALEXI & $5.700 \times 10^{-4}$ & 0.212 \\
\hline Noah & $2.793 \times 10^{-4}$ & 0.387 \\
\hline
\end{tabular}

observing systems and models often provide complementary estimates of a single variable. In this study, independent estimates of soil moisture derived from passive microwave (AMSR-E; LPRM), thermal infrared (ALEXI), and modelbased (Noah) methods were cross-compared and merged into a single consensus drought monitor product using triple collocation analysis. It was found that ALEXI complements the poor performance of LPRM under conditions of dense vegetation, while LPRM and Noah provide more consistent anomaly estimates under more sparse vegetation conditions. This general pattern, which derives from the fact that vegetation interferes with LPRM soil moisture retrievals but does not compromise thermally derived soil moisture estimates from ALEXI, is consistent with findings of Hain et al. (2011) for the contiguous US. The least squares-based objective data merging technique that is built over the TCA-based error estimates utilizes the complementary strengths of each method to generate soil moisture anomaly estimates across agroclimatic zones.

While the present study is limited by short satellite data records and an absence of direct in situ soil moisture evaluation data, the consistency of the results with studies in the US and the coherency of independent satellite and model-based analyses of the 2010-2011 Horn of Africa drought point to the promise of the least squares-based merging approach that utilizes TCA-based errors. ALEXI, AMSR-E, Noah, and the merged product all credibly capture the major 2010-2011 drought event, the relative dryness rankings of each year, and the expected seasonal cycles of soil moisture. In addition, 


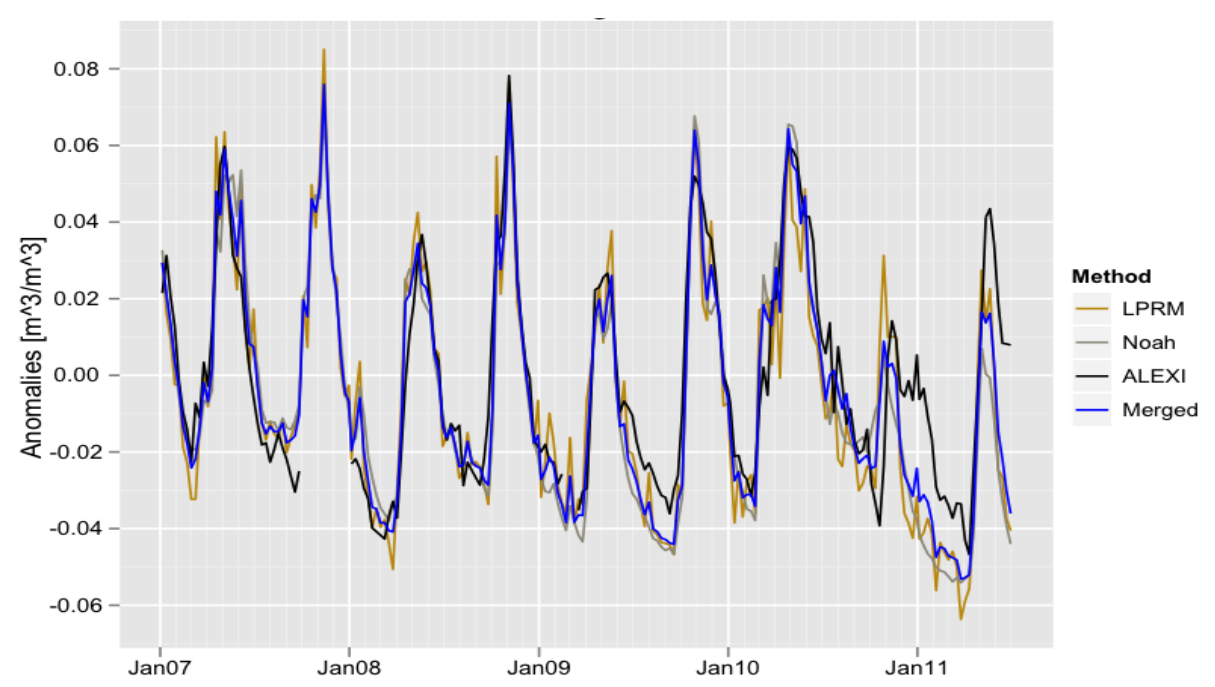

Fig. 12. Comparison of anomalies from individual and merged products using a January 2007-June 2010 baseline, averaged over the area of interest within the Horn of Africa (see Fig. 1).

Table 4. Average merging weight and TC error values for northern Lake Victoria.

\begin{tabular}{lcc}
\hline \multicolumn{3}{c}{ Northern Lake Victoria } \\
$(28.71,35.95,-0.25,3.65)$ & {$[\mathrm{W}, \mathrm{E}, \mathrm{S}, \mathrm{N}]$} \\
\hline Retrieval & $\begin{array}{c}\text { Average TCA } \\
\text { value } \\
{\left[\left(\mathrm{m}^{3} \mathrm{~m}^{-3}\right)^{2}\right]}\end{array}$ & $\begin{array}{c}\text { Average } \\
\text { merging } \\
\text { weight }\end{array}$ \\
\hline LPRM & $4.867 \times 10^{-4}$ & 0.273 \\
ALEXI & $5.187 \times 10^{-4}$ & 0.330 \\
Noah & $3.331 \times 10^{-4}$ & 0.396 \\
\hline
\end{tabular}

Table 5. Average anomaly correlations.

\begin{tabular}{lcccc}
\hline Retrieval pair & Darfur & $\begin{array}{c}\text { Ethiopian } \\
\text { Highlands }\end{array}$ & $\begin{array}{c}\text { Horn of } \\
\text { Africa }\end{array}$ & $\begin{array}{c}\text { Northern } \\
\text { Lake } \\
\text { Victoria }\end{array}$ \\
\hline Noah - LPRM & 0.848 & 0.737 & 0.828 & 0.689 \\
ALEXI - LPRM & 0.798 & 0.720 & 0.773 & 0.636 \\
Noah - ALEXI & 0.796 & 0.781 & 0.777 & 0.711 \\
\hline
\end{tabular}

the TMPA precipitation product used to force Noah simulations has demonstrated good performance in the droughtaffected portion of the study region, which lends additional confidence to the Noah results. With the addition of a longer ALEXI time series, the sampling errors that arise from short satellite data records are expected to decrease relative to the current study.

While data merging offers several advantages over a single-source product - including improved spatial coverage relative to single sensor techniques, the potential to downweight products with systematic biases in certain locations or
Table 6. Rank order of long and short rainy seasons based on severity of soil moisture deficit. ALEXI data are missing for the period of the 2007 short rains.

\begin{tabular}{clcccc}
\hline \multirow{2}{*}{2007} & ALEXI & LPRM & Noah & $\begin{array}{c}\text { Merged } \\
\text { product }\end{array}$ \\
\hline \multirow{2}{*}{2008} & Long rains & 6 & 7 & 7 & 7 \\
& Short rains & NA & 9 & 8 & 8 \\
& Long rains & 3 & 4 & 4 & 4 \\
& Short rains & 7 & 6 & 6 & 6 \\
\multirow{2}{*}{2009} & Long rains & 4 & 3 & 3 & 3 \\
& Short rains & 5 & 5 & 5 & 5 \\
\multirow{2}{*}{2011} & Long rains & 8 & 8 & 9 & 9 \\
& Short Rains & $\mathbf{1}$ & $\mathbf{2}$ & $\mathbf{2}$ & $\mathbf{2}$ \\
& Long Rains & $\mathbf{2}$ & $\mathbf{1}$ & $\mathbf{1}$ & $\mathbf{1}$ \\
\hline
\end{tabular}

Numbers in bold indicate the 2010-2011 drought.

environments, and the utilization of information from multiple independent data streams - merging on the basis of consensus alone should properly be viewed as an experimental, transitional approach pending confirmation with in situ data. The merging technique would, for example, tend to propagate any bias that exists in two or more products, possibly degrading performance relative to a single-source product that does not suffer from such bias. In the absence of ground truth, the weighted merging technique proposed in this paper is justified by the well-understood physical processes that underlie general patterns in TCA values most notably the gradient towards degraded AMSR-E performance in densely vegetated regions - and the expectation that there is some information in consensus between independent products, such that a TCA-weighted merged value that captures systematic deviations of one product from the others 
is, on the balance, better justified than a flat average across products and is preferable to relying on a single product with data gaps.

Pending further evaluation, the TCA-based data merging technique could form the foundation for a soil moisture-based drought monitor in East Africa. Such a product would complement existing drought analysis tools that are based on precipitation anomaly, hydrological models, or vegetation indices. Implementation of an operational TCAbased system would, of course, entail a number of practical challenges. First, data latency would need to be addressed. The real-time TMPA 3B42-RT product is typically produced with a $9 \mathrm{~h}$ latency, while LPRM data are produced with a lag of $24 \mathrm{~h}$. ALEXI data latency is currently a function of the accessibility of Meteosat data (e.g., land surface temperature, incoming solar radiation) and processing time for the regional numerical weather prediction (NWP) model used to generate necessary meteorological data fields. In an operational context, it should be possible to make use of operational NWP models (e.g., Global Forecast System or European Centre for Medium-Range Weather Forecasts) to provide the necessary meteorological fields facilitating a rapid product turnaround on the order of $12-24 \mathrm{~h}$. TCA analysis itself can be automated to require minimal processing time, and results can be disseminated through a web interface or email alerts. As such, system latency represents a surmountable challenge for operational monitoring. A second challenge is that the analysis system currently makes use of research-grade remote sensing products, including TMPA precipitation and AMSR-E soil moisture, that are subject to active algorithm development and - as was recently experienced with AMSR-E - failure of one-of-a-kind sensors. The challenge of evolving retrieval algorithms can be overcome with regular recalibration of the analysis system - TCA analysis and data merging can readily be recalculated as data are updated, provided that the updates are applied consistently to the historical data archive. The problem of data continuity in research-grade products is more difficult to address, and points to the value of flexible analysis systems that can be adapted to new satellite products (e.g., using SMAP in place of AMSR-E for soil moisture) and, ultimately, the value of transitioning application-oriented research sensors to operational status.

As demonstrated in this study, diverse satellite- and modelbased monitoring methodologies provide complementary information on the evolution and severity of drought. Ultimately, East Africa - and other drought prone regions would benefit from an accessible and intuitive drought portal that allows drought analysts and decision makers real-time access to a range of drought monitoring products. As a component of a much broader movement for drought preparedness and response capacity in the region, such a monitor can provide valuable information to inform early warning and disaster response for future droughts.
Acknowledgements. This study was supported in part by NASA Applied Sciences grant NNX09AT61G.

Edited by: B. van den Hurk

\section{References}

Albergel, C., Rüdiger, C., Pellarin, T., Calvet, J.-C., Fritz, N., Froissard, F., Suquia, D., Petitpa, A., Piguet, B., and Martin, E.: From near-surface to root-zone soil moisture using an exponential filter: an assessment of the method based on in-situ observations and model simulations, Hydrol. Earth Syst. Sci., 12, 1323-1337, doi:10.5194/hess-12-1323-2008, 2008.

Anderson, M. C., Norman, J. M., Diak, G. R., Kustas, W. P., and Mecikalski, J. R.: A two-source time-integrated model for estimating surface fluxes using thermal infrared remote sensing, Remote Sens. Environ., 60, 195-216, 1997.

Anderson, M. C., Normal, J. M., Kustas, W. P., Li, F., Prueger, J. H., and Mecikalski, J. R.: A climatological study of evapotranspiration and moisture stress across the continental United States: 1. Model formulation, J. Geophys. Res., 112, D11112, doi:10.1029/2006JD007506, 2007a.

Anderson, M. C., Norman, J. M., Mecikalski, J. R., Otkin, J. P., and Kustas, W. P.: A climatological study of evapotranspiration and moisture stress across the continental U.S. based on thermal remote sensing: II. Surface moisture climatology, J. Geophys. Res., 112, D11112, doi:10.1029/12006JD007507, $2007 \mathrm{~b}$.

Anderson, M. C., Hain, C., Pimstein, A., Mecikalski, J. R., and Kustas, W. P.: Evaluation of Drought Indices Based on Thermal Remote Sensing of Evapotranspiration over the Continental United States, J. Climate, 24, 2025-2044, doi:10.1175/2010JCLI3812.1, 2011 a.

Anderson, M. C., Kustas, W. P., Norman, J. M., Hain, C. R., Mecikalski, J. R., Schultz, L., González-Dugo, M. P., Cammalleri, C., d'Urso, G., Pimstein, A., and Gao, F.: Mapping daily evapotranspiration at field to continental scales using geostationary and polar orbiting satellite imagery, Hydrol. Earth Syst. Sci., 15, 223-239, doi:10.5194/hess-15-223-2011, 2011 b.

Burnash, R. J. C.: The NWS River Forecast System - catchment modeling, in: Computer Models of Watershed Hydrology, edited by: Singh, V. P., Water Resources Publications, Highlands Ranch, CO, 311-366, 1995.

Brown, J. F.: Drought Monitoring with VegDRI, US Geological Survey Fact Sheet 2010-3114, US Geological Survey, p. 2, 2010.

Ceballos, A., Scipal, K., Wagner, W., and Martinez-Fernandez, J.: Validation of ERS scatterometer derived soil moisture data in the central part of the Duero Basin, Spain, Hydrol. Process., 25, 1549-1566, 2005.

Chen, F., Mitchell, K., Schaake, J., Xue, Y., Pan, H., Koren, V., Duan, Y., Ek, M., and Betts, A.: Modeling of land-surface evaporation by four schemes and comparison with FIFE observations, J. Geophys. Res., 101, 7251-7268, doi:10.1029/95JD02165, 1996.

Crow, W. T. and Zhan, X.: Continental-scale evaluation of remotelysensed soil moisture products, IEEE Geosci. Remote Sens. Lett., 4, 451-455, 2007.

Crow, W. T., Miralles, D. G., and Cosh, M. H.: A Quasi-Global Evaluation System for Satellite-Based Surface Soil Moisture Retrievals, IEEE T. Geosci. Remote, 48, 2516-2527, 2010. 
Dai, Y., Zeng, X., Dickinson, R. E., Baker, I., Bonan, G. B., Bosilovich, M. G., Denning, A. S., Dirmeyer, P. A., Houser, P. R., Niu, G., Oleson, K. W., Schlosser, C. A., and Yang, Z. L.: The Common Land Model, B. Am. Meteorol. Soc., 84, 10131023, 2003.

Derber, J. C., Parrish, D. F., and Lord, S. J.: The new global operational analysis system at the National Meteorological Center, Weather Forecast., 6, 538-547, 1991.

Draper, C. S., Walker, J. P., Steinle, P. J., De Jeu, R. A. M., and Holmes, T. R. H.: An evaluation of AMSR-E derived soil moisture over Australia, Remote Sens. Environ., 113, 703-710, 2009.

Ek, M. B., Mitchell, K. E., Lin, Y., Rogers, E., Grunmann, P., Koren, V., Gayno, G., and Tarpley, J. D.: Implementation of Noah land surface model advances in the National Centers for Environmental Prediction operational mesoscale Eta model, J. Geophys. Res., 108, 8851, doi:10.1029/2002JD003296, 2003.

Funk, C.: New Satellite Observations and Rainfall Forecasts Help Provide Earlier Warning of African Drought, Earth Observ., 21, 23-27, 2009.

Funk, C.: We thought trouble was coming, Nature, 476, 7, doi:10.1038/476007a, 2011.

Gutman, G. and Ignatov, A.: The derivation of the green vegetation fraction from NOAA/AVHRR data for use in numerical weather prediction models. Int. J. Remote Sens., 19, 1533-1543, 1998.

Hain, C. R., Mecikalski, J. R., and Anderson, M. C.: Retrieval of an available water-based soil moisture proxy from thermal infrared remote sensing, Part I: Methodology and Validation, J. Hydrometeorol., 10, 665-683, 2009.

Hain, C. R., Crow, W. T., Mecikalski, J. R., Anderson, M. C., and Holmes, T.: An Intercomparison of Available Soil Moisture Estimates from Thermal-Infrared and Passive Microwave Remote Sensing and Land-surface Modeling, J. Geophys. Res., 116, D15107, doi:10.1029/2011JD015633, 2011.

Huete, A., Didan, K., Miura, T., Rodriguez, E. P., Gao, X., and Ferreira, L. G.: Overview of the radiometric and biophysical performance of the MODIS vegetation indices, Remote Sens. Environ., 83, 195-213, 2002.

Huffman, G., Adler, R. F., Bolvin, D. T., Gu, G., Nelkin, E. J., Bowman, K. P., Hong, Y., Stocker, E. F., and Wolff, D. B.: The TRMM Multisatellite Precipitation Analysis (TMPA): QuasiGlobal, Multiyear, Combined-Sensor Precipitation Estimates at Fine Scales, J. Hydrometeorol., 8, 38-55, 2007.

Janowiak, J. E. and Xie, P.: CAMS_OPI: a global satellite-raingauge merged product for real-time precipitation monitoring applications, J. Climate, 12, 3335-3342, 1999.

Janssen, P., Abdalla, S., Hersbach, H., and Bidlot, J. R.: Error Estimation of Buoy, Satellite, and Model Wave Height Data, J. Atmos Ocean. Tech., 24, 1665-1677, 2007.

Kerr, Y. H. and Njoku, E. G.: A semiempirical model for interpreting microwave emission from semiarid land surfaces as seen from space, IEEE T. Geosci. Remote, 28, 384-393, 1990.

Kogan, F. N.: Remote sensing of weather impacts on vegetation in non-homogeneous areas, Int. J. Remote Sens., 11, 1405-1419, 1990.

Kogan, F. N.: Droughts of the late 1980s in the U.S. as derived from NOAA polar-orbiting satellite data, B. Am. Meteorol. Soc., 76, 655-668, 1995.

Kogan, F. N.: Global Drought Watch from Space, B. Am. Meteorol. Soc., 78, 621-636, 1997.
Koren, V., Schaake, J., Mitchell, K., Duan, Q. Y., Chen, F., and Baker, J. M.: A parameterization of snowpack and frozen ground intended for NCEP weather and climate models, J. Geophys. Res., 104, 19569-19585, doi:10.1029/1999JD900232, 1999.

Koster, R. D. and Suarez, M. J.: Energy and water balance calculations in the Mosaic LSM, NASA Tech. Memo. 104606, 76, Goddard Space Flight Center, Greenbelt, MD, 1996.

Koster, R. D., Suarez, M. J., Ducharne, A., Stieglitz, M., and Kumar, P.: A catchment-based approach to modeling land surface processes in a GCM, Part 1, Model Structure, J. Geophys. Res., 105, 24809-24822, 2000.

Lawrence, D. M., Oleson, K. W., Flanner, M. G., Thornton, P. E., Swenson, S. C., Lawrence, P. J., Zeng, X., Yang, Z.-L., Levis, S., Sakaguchi, K., Bonan, G. B., and Slater, A. G.: Parameterization improvements and functional and structural advances in version 4 of the Community Land Model, J. Adv. Model. Earth Syst., 3, M03001, doi:10.1029/2011MS000045, 2011.

Ledwith, T.: Crisis in the Horn of Africa: Rethinking the Humanitarian Response, 5 October 2011, http://reliefweb.int/node/ 4512333, last access: 20 November 2011.

Liang, X., Lettenmaier, D. P., Wood, E. F., and Burges, S. J.: A simple hydrologically based model of land surface water and energy fluxes for GCMs, J. Geophys. Res., 99, 14415-14428, 1994.

Njoku, E. G., Chan, T., Crosson, W., and Limaye, A.: Evaluation of the AMSR-E Data Calibration Over Land, Ital. J. Remote Sens., 30/31, 19-37, 2004.

Norman, J. M., Kustas, W. P., and Humes, K. S.: Source approach for estimating soil and vegetation energy fluxes in observations of directional radiometric surface-temperature, Agr. Forest Meteorol., 77, 263-293, 1995.

Owe, M., De Jeu, R. A. M., and Holmes, T. R. H.: MultiSensor Historical Climatology of Satellite-Derived Global Land Surface Moisture, J. Geophys. Res., 113, F01002, doi:1029/2007JF000769, 2008.

Parinussa, R. M., Holmes, T. R. H., Yilmaz, M. T., and Crow, W. T.: The impact of land surface temperature on soil moisture anomaly detection from passive microwave observations, Hydrol. Earth Syst. Sci., 15, 3135-3151, doi:10.5194/hess-15-31352011, 2011.

Rudiger, C., Jean-Christophe, C., Gruhier, C., Holmes, T. R. H., De Jeu, R. A. M., and Wagner, W.: An Intercomparison of ERS-Scat and AMSR-E Soil Moisture Observations with Model Simulations over France, J. Hydrometeorol., 10, 431-447, 2009.

Scipal, K., Holmes, T., de Jeu, R., Naeimi, V., and Wagner, W.: A possible solution for the problem of estimating the error structure of global soil moisture data sets, Geophys. Res. Lett., 35, L24403, doi:10.1029/2008GL035599, 2008.

Sheffield, J., Wood, E. F., Lettenmaier, D. P., and Lipponen, A.: Experimental Drought Monitoring for Africa, GEWEX News, 8, International GEWEX Project Office, Silver Spring, Maryland, 2008.

Sheffield, J., Xia, Y., Luo, L., Wood, E. F., Ek, M., Mitchell, K. E., and the NLDAS Team: Drought Monitoring with the North American Land Data Assimilation System (NLDAS): A Framework for Merging Model and Satellite Data for Improved Drought Monitoring, in: Remote Sensing of Drought: Innovative Monitoring Approaches, edited by: Wardlow, B., Anderson, M., and Verdin, J., Taylor and Francis, London, UK, p. 270, 2012. 
Stoffelen, A.: Toward the true near-surface wind speed: Error modeling and calibra- tion using triple collocation, J. Geophys. Res., 103, 7755-7766, 1998.

Swenson, S. C. and Wahr, J.: Post-processing removal of correlated errors in GRACE data, Geophys. Res. Lett., 33, L08402, doi:10.1029/2005GL025285, 2006.

USAID FEWS NET - United States Agency for International Development, Famine Early Warning System Network, East Africa: Past year one of the driest on record in the eastern Horn, http://www.fews.net/docs/Publications/FEWS\%20NET\% 20EA_Historical\%20drought\%20context_061411.pdf, last access: 14 June 2011.

United Nations Office for the Coordination of Humanitarian Affairs: Horn of Africa Crisis Situation Report No. 18, 14 October 2011.

United Nations - UN News Center: UN Declares Famine in Another Three Areas of Somalia, http://www.un.org/apps/news/story.asp? NewsID=39225, last access: 3 August 2011.

Wagner, W., Lemoine, G., and Rott, H.: A method for estimating soil moisture from ERS scatterometer and soil data, Remote Sens. Environ., 70, 191-207, 1999.

Wagner, W., Naeimi, V., Scipal, K., De Jeu, R., and MartinezFernandez, J.: Soil moisture from operational meterologival satellites, Hydrogeol. J., 15, 121-131, 2007.

Wood, A. W.: The University of Washington Surface Water Monitor: An experimental platform for national hydrologic assessment and prediction. Proceedings of the AMS 22nd Conference on Hydrology, New Orleans, 13 pages, 20-24 January 2008.
Xia, Y., Mitchell, K., Ek, M., Sheffield, J., Cosgrove, B., Wood, E. F., Luo, L., Alonge, C., Wei, H., Meng, J., Livneh, B., Lettenmaier, D., Koren, V., Duan, Q., Mo, K., Fan, Y., and Mocko, D.: Continental-Scale Water and Energy Flux Analysis and Validation for the North-American Land Data Assimilation System Project Phase 2 (NLDAS-2), Part 1: Intercomparison and Application of Model Products, J. Geophys. Res., 117, D03110, doi:10.1029/2011JD016051, 2012.

Yilmaz, M. T., Crow, W. T., Anderson, M. C., and Hain, C.: An Objective Methodology for Merging Satellite- and Model-Based Soil Moisture Products, Water Resour. Res., submitted, 2012.

Zaitchik, B. F., Rodell, M., and Reichle, R. H.: Assimilation of GRACE terrestrial water storage data into a land surface model: results for the Mississippi River Basin, J. Hydrometeorol., 9, 535-548, doi:10.1175/2007JHM951.1, 2008.

Zaitchik, B. F., Habib, S., Anderson, M., Ozdogan, M., and Alo, C.: A Land Data Assimilation System for hydrologic studies in countries of the Nile basin, 8th International Conference of the African Association of Remote Sensing for the Environment, Addis Ababa, Ethiopia, 2010.

Zwieback, S., Scipal, K., Dorigo, W., and Wagner, W.: Structural and statistical properties of the collocation technique for error characterization, Nonlin. Processes Geophys., 19, 69-80, doi:10.5194/npg-19-69-2012, 2012. 